\title{
The Representation of S-Cone Signals in Primary Visual Cortex
}

\author{
Elizabeth N. Johnson, ${ }^{\star \star}$ Stephen D. Van Hooser, ${ }^{2 *}$ and David Fitzpatrick ${ }^{1,2}$ \\ ${ }^{1}$ Duke Institute for Brain Sciences, Duke University and ${ }^{2}$ Department of Neurobiology, Duke University Medical Center, Durham, North Carolina 27710
}

Recent studies of middle-wavelength-sensitive and long-wavelength-sensitive cone responses in primate primary visual cortex (V1) have challenged the view that color and form are represented by distinct neuronal populations. Individual V1 neurons exhibit hallmarks of both color and form processing (cone opponency and orientation selectivity), and many display cone interactions that do not fit classic chromatic/achromatic classifications. Comparable analysis of short-wavelength-sensitive (S) cone responses has yet to be achieved and is of considerable interest because S-cones are the basis for the primordial mammalian chromatic pathway. Using intrinsic and twophoton imaging techniques in the tree shrew, we assessed the properties of V1 layer 2/3 neurons responsive to S-cone stimulation. These responses were orientation selective, exhibited distinct spatiotemporal properties, and reflected integration of S-cone inputs via opponent, summing, and intermediate configurations. Our observations support a common framework for the representation of cone signals in V1, one that endows orientation-selective neurons with a range of chromatic, achromatic, and mixed response properties.

\section{Introduction}

For most mammals, color vision is dichromatic, limited to comparisons (opponency) between two cone types: a short-wavelengthsensitive (S) cone and a long-wavelength-sensitive (L) cone (Peichl, 2005). This S-cone-opponent system is augmented in some primates, including humans, with an additional cone type allowing finer color discriminations by comparing the responses of L-cone and middle-wavelength-sensitive (M) cones. Thus, the S-coneopponent system represents the primordial color system common to most mammals: the basis of color vision in dichromats and the source of sensitivity to the blue end of the spectrum in trichromatic primates.

Despite the fundamental role of S-cone signals in mammalian color vision, our understanding of the cortical representation of these signals lags far behind our knowledge of L-and M-cone signals. In part, this reflects the fact that S-cones make up $<10 \%$ of the photoreceptors in the retina, and relatively few S-coneresponsive cells have been encountered in previous studies (Malpeli and Schiller, 1978; de Monasterio, 1979; Zrenner and Gouras, 1981; Derrington et al., 1984; Valberg et al., 1986; Lennie et al., 1990; Reid and Shapley, 2002; Dacey and Packer, 2003; Johnson et al., 2004, 2008; Horwitz et al., 2005; Conway and Livingstone, 2006; Szmajda et al., 2006; Field et al., 2007). Nevertheless, human functional magnetic resonance imaging (fMRI)

Received March 18, 2010; revised June 14, 2010; accepted June 15, 2010.

This work was supported by National Institutes of Health (NIH) Grant EY-006821 and NIH F32 Grants EY-015357 and EY-018064. We thank members of the Fitzpatrick Laboratory: Julie Heiner and Drs. Wei Wu, Ye Li, Rebekah Corlew, Xiaoying Huang, Yishai Elyada, Len White, Sean MacEvoy, and Thomas Tucker for help during the development of the project; and Dr. Robert Shapley for helpful comments on this manuscript.

*E.N.J. and S.D.V.H. contributed equally to this work.

Correspondence should be addressed to Elizabeth Johnson, B107 LSRC, Box 91003, Duke University, Durham, NC 27708. E-mail: johnson@neuro.duke.edu.

S. D. Van Hooser's present address: Department of Biology, Brandeis University, MS 008, Waltham, MA 02454. DOI:10.1523/JNEUROSCI.1428-10.2010

Copyright $\odot 2010$ the authors $\quad 0270-6474 / 10 / 3010337-14 \$ 15.00 / 0$ studies indicate that S-cones contribute significantly to the activation of neurons in primary visual cortex (V1) and in extrastriate areas, with a magnitude that belies the sparse retinal sampling of the system and with temporal properties that are distinct from the ML-cone-opponent system (Kleinschmidt et al., 1996; Engel et al., 1997; Wandell, 1999; Liu and Wandell, 2005; Mullen et al., 2007, 2008; Sumner et al., 2008).

Understanding the central representation of S-cone signals is especially relevant for resolving the larger question of how color and form are represented within V1. Historically, form vision was thought to depend primarily on achromatic information supplied by neurons sensitive to edges defined by luminance cues. This perspective was reinforced by evidence from V1 single-unit studies indicating that color selectivity and orientation selectivity are mutually exclusive (Livingstone and Hubel, 1984; Ts'o and Gilbert, 1988; Lennie et al., 1990). However, other studies, mostly of the ML-opponent system, have found that neurons could exhibit orientation selectivity regardless of their selectivity for stimulus color (Thorell et al., 1984; Leventhal et al., 1995; Johnson et al., 2001, 2008; Friedman et al., 2003; Heimel et al., 2005; Conway and Livingstone, 2006). The response of neurons to both form and color could be unique to the ML-opponent system, reflecting its emergence relatively late in evolution within a parvocellular pathway that was already specialized for high acuity form vision. If so, more robust segregation of color and form might be expected in the phylogenetically older S-cone-opponent system that is relayed through a separate set of LGN layers ("koniocellular, or "K", layers) that are not thought to contribute to high acuity form vision (Hendry and Reid, 2000; Calkins, 2001; Chatterjee and Callaway, 2003).

In this study, we sought insights into the fundamental features of cortical organization necessary for S-cone-mediated color vision by examining the cortical processing of S-cone inputs in the tree shrew, a highly visual dichromatic mammal with a cone-dominated retina, 
strong color vision capabilities, and a well characterized V1 functional architecture (Jacobs and Neitz, 1986; Petry and Hárosi, 1990; Petry and Kelly, 1991; Muly and Fitzpatrick, 1992; Fitzpatrick, 1996; Bosking et al., 1997, 2002; van Arsdel and Loop, 2004). Our results indicate that S-cones contribute to both chromatic and achromatic visual functions and suggest that the conjoint representation of color and form is a fundamental property of cortical processing.

\section{Materials and Methods}

Animal preparation. For all experiments, tree shrews were anesthetized with a mixture of ketamine $(200 \mathrm{mg} / \mathrm{kg})$ and xylazine $(4.7 \mathrm{mg} / \mathrm{kg})$ by intramuscular injection, shaved, prepped, and intubated. They were placed in a modified stereotaxic frame that does not obstruct the field of view. Throughout the remainder of the surgical procedure, the animal was administered a mixture of $\mathrm{N}_{2} \mathrm{O} / \mathrm{O}_{2}(2: 1)$ supplemented with halothane (extracellular recording and intrinsic imaging) or isoflurane (twophoton experiments), as needed $(0.5-2 \%)$. Body temperature was maintained by a thermostatically controlled heating blanket, and expired $\mathrm{CO}_{2}$ and heart rate were monitored for any signs of distress. Contact lenses were placed on the eyes for protection and to focus them on the computer monitor used for stimulus presentation. All pressure points and incisions were infiltrated with $10-30 \mu \mathrm{l}$ of a long-acting local anesthetic (bupivacaine, $2.5 \mathrm{mg} / \mathrm{ml}$ ). Once the surgical portion of the experiment was concluded, the $\mathrm{N}_{2} \mathrm{O} / \mathrm{O}_{2}$ mixture was reduced to $1: 1$, and the halothane or isoflurane level was decreased to $0.5-0.75 \%$. Pancuronium bromide $(0.2 \mathrm{mg} / \mathrm{h})$ was used as a paralytic to prevent eye movements, and the animal was respired at a level that maintained expired $\mathrm{CO}_{2}$ at $3.5 \%$. The electrocardiogram was monitored for any signs of distress, which was ameliorated by increasing the anesthetic levels.

All procedures conformed to the guidelines approved by the Duke University Animal Care and Use Committee and were done in compliance with guidelines published by the National Institutes of Health.

Intrinsic signal optical imaging. Intrinsic signal optical imaging takes advantage of the fact that the optical properties of brain tissue change as a result of changes in metabolic activity. By illuminating the cortical surface with red light $(690 \mathrm{~nm})$, it is possible to detect the oxyhemoglobin-to-hemoglobin transition that occurs in response to metabolic demands. The skull overlying the visual cortex was thinned using a scalpel blade until it was almost transparent. A chamber was affixed to the skull and filled with 1\% agar. A round glass "window" in the chamber allowed viewing of the surface of the brain. The cortical surface was visualized through a tandem lens macroscope attached to a low-noise video camera. The signal from the video camera was digitized for storage and additional processing. Data acquisition was accomplished with a software system from Optical Imaging.

Optical imaging analysis. Initial image analysis was performed with custom software written in Matlab (MathWorks) by Dr. T. Tucker (Gustavus Adolphus College, St. Peter, MN). To quantify stimulusevoked signal changes, the first frame from each trial was subtracted from each subsequent frame on a pixel-by-pixel basis. Because no stimulus was present during acquisition of the first frame, it serves as a reference against which stimulus-evoked changes in reflected light can be observed. Because of its proximity in time to the data frames it serves, using the first frame as a reference is more effective in mitigating the effects of slow drifts in overall activity and the appearance of vascular artifacts than a blank or "cocktail" reference. First frame-subtracted pixel maps were next divided by the first frame pixel values to discount differences in illumination intensity and accurately extract changes in cortical reflectance. In the resulting pixel maps, a value of zero corresponds to no change in reflectance between a given data frame and the reference; values above and below zero indicate increases and decreases in reflectance relative to the reference, respectively. Next, the first frame in which a stimulus was present was discarded, and the remainder was averaged across all trials to reduce noise. Images were typically the result of averaging across 40-100 trials. Using NIH ImageJ software, average images were smoothed with a 1- to 12-pixel-diameter mean filter and high-pass filtered by convolving them with an 80 - to 120 -pixel-diameter mean filter and subtracting the result from the original image. Images were typically clipped at 2 SDs for display.

To calculate the orientation tuning of the population response, we presented full-screen sinusoidal cone-isolating grating stimuli at eight orientations $\left(0^{\circ}-157.5^{\circ}\right.$, at $22.5^{\circ}$ intervals $)$, at a spatial frequency of 0.2 cycles $/^{\circ}$ (cpd) and a temporal frequency of $3 \mathrm{~Hz}$. Orientation tuning curves were generated for each pixel using the $\Delta R / R$ values for the response to each stimulus orientation, and these curves were fit with a circular Gaussian (equation below).

Spatial and temporal frequency tuning curves were computed by calculating the mean $\Delta R / R$ in a region of interest that was free of surface blood vessels; images from four orientations $\left(0^{\circ}, 45^{\circ}, 90^{\circ}\right.$, and $\left.135^{\circ}\right)$ were added together for each spatial or temporal frequency and each coneisolating stimulus to obtain the values reported in Figure 3. To calculate the average response across animals, the responses were normalized between 0 (minimum) and 1 (maximum), the normalized response to the blank stimulus was subtracted, and the mean values for each frequency were computed.

Extracellular recording. The skull overlying visual cortex was thinned, a hole was made in the cranium, and the dura was removed. A tungsten microelectrode (FHC Inc.) or a carbon fiber multibarrel electrode (Kation Scientific) attached to a hydraulic microdrive was then inserted into the cortex. Records of multiunit and single-unit activity occurring in response to visual stimuli were stored using a CED-1401+ (Cambridge Electronic Design) interface attached to a computer, and the waveforms of individual neurons were isolated using Spike2 software (Cambridge Electronic Design). At the conclusion of physiological recoding, small lesions (3-4 $\mu \mathrm{A}, 4 \mathrm{~s}$, electrode tip negative) were made to permit confirmation of the location of the recording site.

Two-photon imaging. A stainless steel head plate with a $10 \times 6 \mathrm{~mm}$ opening was attached to the skull with dental caulk (Dentsply). For each hemisphere, a small craniotomy (2-3 $\mathrm{mm}$ in diameter) was performed over visual cortex, and one to three sites were injected with the calcium dye Oregon green BAPTA-1 (Invitrogen). The injections and imaging procedures were as described previously (Li et al., 2008), except that, in the tree shrew, the dura was left intact during the dye injections, and no agarose was used during the dye injections. The dura was removed immediately before imaging. The site with the best dye uptake (visual inspection) was used for the remainder of the experiment.

Two-photon images were analyzed with custom software written in Matlab and C as described in detail previously (Li et al., 2008). In brief, cells were identified by the experimenter, and the fluorescence of each cell was computed by averaging all pixels within a region of interest of radius 12 pixels that was centered on the soma. Image series taken at different times were aligned using full-image correlation, followed by small manual corrections for each cell. The entire process of cell identification was done blind to subsequent analyses of physiological responses. The response to each stimulus was calculated as $\frac{\Delta F}{F}=\frac{\left(F_{\text {STIM }}-F_{0}\right)}{F_{0}}$, where $F_{\text {STIM }}$ is the average response during each frame when the stimulus was on, and $F_{0}$ is the average response during the final $3 \mathrm{~s}$ of the interstimulus period before stimulus onset. Visual stimuli for two-photon experiments were presented for $5 \mathrm{~s}$, with a $5 \mathrm{~s}$ interstimulus interval.

Visual stimulation. Visual stimuli were generated on a Macintosh G4 computer using Matlab and the Psychophysics Toolbox (Brainard, 1997; Pelli, 1997). Stimuli were displayed on a gamma-corrected Sony GDM F520 color monitor measuring $40.4 \mathrm{~cm}$ wide and $30.2 \mathrm{~cm}$ high, with a resolution of $800 \times 600$ pixels. The refresh rate of the monitor was 100 $\mathrm{Hz}$, with a mean luminance of $54 \mathrm{~cd} / \mathrm{m}^{2}$. The chromaticity of the background was $x=0.291, y=0.307$. All color modulation was around this white point. The stimuli were viewed at a distance of $27.6 \mathrm{~cm}$. Drifting gratings for two-photon experiments had spatial frequencies ranging between 0.2 and $0.4 \mathrm{cpd}$ and temporal frequencies ranging from 2 to $4 \mathrm{~Hz}$.

Cone-isolating stimuli and color exchange. The cone absorption functions for tree shrew S- and ML-cones were kindly provided by Dr. Heywood Petry (University of Louisville, Louisville, KY) (Petry and Hárosi, 1990). ML-cone-isolating stimuli were generated by modulating the green and blue cathode ray tube (CRT) guns at a ratio designed to null the 
S-cone response based on calculations of S-cone excitation. S-cone excitation was calculated as the dot product of the cone absorption functions and the spectral energy distribution of the gun primaries at half power measured at a $2 \mathrm{~nm}$ resolution with an Analytical Spectral Devices spectroradiometer. The S-cone-isolating stimulus was determined empirically using the method of color exchange (Estévez and Spekreijse, 1982), using modulation in only the blue and green guns. Because $\sim 90 \%$ of the cones in the tree shrew retina are of the ML type (Müller and Peichl, 1989), adjustments in the blue/green ratio result in a prominent response minimum or null at the gun values that yield no modulation of the ML-cones. The blue CRT gun modulation was held constant at 0.8 maximum, and the green gun contrast was varied from 0 to -0.8 (modulation depth is negative because the green and blue guns were modulated in antiphase) producing heterochromatic blue/green sinusoidal gratings. To make direct comparisons of the responses to the different coneisolating stimuli, it is necessary to express the intensities of the stimuli in common units. Therefore, the relative excitation of each class of photoreceptor produced by the stimulus [the cone contrast (CC)] was the same for the ML- and S-cone-isolating stimulus types. Cone contrast was calculated as the summed modulation of the guns for each cone divided by the summed average excitation for each cone. All chromatic stimuli are of the same mean luminance and are of the same mean luminance as the gray "blank" stimulus and the gray background when full-screen gratings were not used.

Color-exchange experiments to verify S-cone isolation were done in 11 multiunit cortical sites from two animals (one male, one female) (see supplemental Fig. S1, available at www.jneurosci.org as supplemental material). The mean response minimum, or null, occurred when the stimulus was modulated at gun values of 0.8 blue: -0.19 green, which, based on cone absorption spectra, is consistent with silencing retinal ML-cones [expected value for 0.8 blue was -0.24 green based on known tree shrew cone absorption curves (Petry and Hárosi, 1990)].

Focus was not adjusted for different colored stimuli; these animals have relatively small eyes and therefore should have a large depth of field (Green et al., 1980).

Single-cell data analysis. In Figure 4, cells were assessed for significant $\mathrm{S}$-cone responses by examining the responses to the blue/green colorexchange stimulus suite described above. Cells were said to exhibit statistically significant $\mathrm{S}$-cone responses if all of the responses to the three stimuli that were chromatically closest to the S-cone-isolating stimulus gave a response that was different from a blank screen (three $t$ tests, $\alpha=$ 0.25 , to have an overall $\alpha=0.05$ ) (supplemental Fig. S1, available at www.jneurosci.org as supplemental material).

Responses to gratings with different orientations were fit (minimizing squared error) with a Gaussian function (Carandini and Ferster, 2000): $R(\theta)=R_{\text {OFFSET }}+R_{\text {PREF }} e^{-\frac{\operatorname{ang}\left(\theta-\theta_{\text {PREF }}\right)^{2}}{2 \sigma^{2}}}$, where $R_{\text {OFFSET }}$ is a constant offset, $\theta_{\text {PREF }}$ is the preferred orientation, $R_{\text {PREF }}$ is the above-offset response to the preferred orientation, $\sqrt{\log 4} \delta$ is the tuning width (halfwidth at half-height), and $\operatorname{ang}(x)=\min (x, x-180, x+180)$ wraps angular difference values onto the interval $0^{\circ}$ to $90^{\circ}$. From these fits, we computed two additional orientation index values: the circular variance

$\mathrm{CV}=1-\left|\sum_{k} R\left(\theta_{k}\right) \exp \left(2 i \theta_{k}\right)\right| / \sum_{k} R\left(\theta_{k}\right)$ and the orthogonal to preferred response ratio $\frac{\mathrm{O}}{\mathrm{P}}=\frac{\left.R\left(\theta_{\mathrm{PREF}}+90\right)-R \text { (blank }\right)}{\left.R\left(\theta_{\mathrm{PREF}}\right)-R \text { (blank }\right)}$.

Responses to 16 combinations of S- and ML-cone contrasts were measured as described in Figure 5. For simplicity, only 12 combinations are shown in the figures, but fits were constructed on responses to four additional stimuli: 90\% S- and ML-cone contrast presented either inphase or out-of-phase, and 25\% S- or ML-cone contrast presented alone. If an ANOVA of the responses indicated that there was significant modulation across the stimuli $(p<0.05)$, the responses were analyzed further. Goodness of fit was calculated as the amount of the response squared that was explained by each fit; we used the total response rather than variation around the mean because none of the models included a constant offset term that could adjust the baseline of the fit.

The best model for each cell was determined by a modified nested $F$ test, which assesses the quality of related models by weighing squared error (lower is better) against the number of free parameters (lower is better) required for each model. The CC model was compared with both the modified CC model and the two-phase model using standard nested $F$ tests. If only one of the modified CC model or the two-phase model was a better fit according to the nested $F$ tests, then that model was deemed the best fit overall. If neither the modified CC model nor the two-phase model was a better fit than the CC model by the nested $F$ tests, then the CC model was deemed best. If both the modified CC model and the two-phase model were better than the CC model according to the nested $F$ tests, then we chose the model that had the least squared error. Cells were said to be "ML-only" if the CC or modified CC model was the best fit, and the sign of the S-cone weight was not consistent in 95 of 100 bootstrap simulations.

To calculate the "cone-summing index", we drew a line in 12dimensional space between two points: one point corresponded to the normalized tuning curve of a model summing neuron $\left(\mathrm{S}_{\mathrm{w}}=\mathrm{ML}_{\mathrm{w}}\right)$ and the other to the normalized tuning curve of a model opponent neuron $\left(\mathrm{S}_{\mathrm{w}}=-\mathrm{ML}_{\mathrm{w}}\right)$. We defined the location of the model summing neuron on this line to have value 1 and defined the location of the model opponent neuron to be -1 . The opponency response index for each neuron was taken to be the closest point on this line to the normalized tuning curve of the neuron. For normalizing, each tuning curve was scaled so that the response to a gray screen was 0 and the maximum response was 1 .

The "S/ML response index" was calculated similarly, except that the two points used to define the line were different. One point corresponded to the normalized tuning curve of a model neuron that only received $\mathrm{S}$-cone drive $\left(\mathrm{S}_{\mathrm{w}}=1, \mathrm{ML}_{\mathrm{w}}=0\right)$, and the other point corresponded to the normalized tuning curve of a model neuron that only received ML-cone input $\left(\mathrm{S}_{\mathrm{w}}=0, \mathrm{ML}_{\mathrm{w}}=1\right)$.

\section{Results}

\section{Intrinsic signal imaging of cone-isolating V1 population responses}

As a first step in assessing S-cone contributions to layer 2/3 of V1, we used intrinsic signal imaging to characterize the population response to $\mathrm{S}$-cone-isolating stimuli, which selectively modulate $\mathrm{S}$-cone responses while keeping the responses of ML-cones constant (unmodulated). The method of color exchange was used to produce a chromatic sine wave grating stimulus that silences the responses of ML-cones but drives the S-cones, the definition of an S-cone-isolating stimulus (see Materials and Methods).

Single-condition images of responses to S- or ML-coneisolating stimuli revealed similar activation patterns for both cone-isolating stimuli (Fig. 1). This pattern was distinctly modular, with a size and spacing consistent with previous descriptions of the columnar mapping of orientation preference in the tree shrew (Humphrey et al., 1980; Bosking et al., 1997). Presentation of vertical and horizontal S-cone-isolating gratings resulted in complementary modular patterns, and subtraction of the two activation patterns resulted in a strong orientation difference signal (Fig. 1A). Moreover, the cortical activation pattern for $\mathrm{S}$-cone-isolating gratings appeared quite similar to that produced by ML-cone-isolating gratings of the same orientation (Fig. 1B), suggesting that both sets of cone inputs are represented within a single map of orientation preference.

To compare these patterns more comprehensively, we obtained intrinsic signal images with $S$ - and ML-cone stimulation to eight stimulus orientations $\left(0^{\circ}-157.5^{\circ}\right.$ in $22.5^{\circ}$ steps, with sinusoidal gratings of $0.2 \mathrm{cpd}$, drifting at $3 \mathrm{~Hz}$ ). To extract orientation preference at each pixel, we fit responses using a circular Gaussian (Fig. 2). Most pixels were well fit by this function (mean $\pm \mathrm{SD}$ ML-cone $R^{2}=0.68 \pm 0.21$, mean S-cone $R^{2}=0.61 \pm 0.23$ ). Low $R^{2}$ values (poor fits) were found to correspond to locations of blood vessels, as well as fractures and singularities, regions in which there was a high rate of change in orientation preference. 
Comparing orientation preference values obtained from S- and ML-cone stimulation revealed a strong correspondence (Fig. 2C,D). Together, these results indicate that both S- and ML-cone inputs contribute to the orientation-tuned responses of layer $2 / 3$ neurons and do so via circuits that construct a single uniform representation of stimulus orientation.

\section{S- and ML-cone cortical responses exhibit distinct spatial and temporal tuning properties}

Although the difference in retinal sampling was not evident in the orientationselective responses to $\mathrm{S}$ - and ML-cone stimulation, it was evident in the magnitude of responses at different spatial frequencies (Fig. $3 A, B$ ). Spatial frequency tuning curves for $\mathrm{S}$ - and ML-coneisolating stimuli derived from the population responses were strikingly different, with S-cone responses peaking at much lower spatial frequencies than ML-cone responses (two-factor ANOVA interaction, $p<0.001)$. Although there were animal-to-animal differences in signal magnitude and optimal spatial frequency, the average activation from S-cone stimuli ( $n=4$ animals) is restricted to low spatial frequencies $(0.025-$ $0.55 \mathrm{cpd}$ ) (Fig. $3 B$ ). In contrast, activation with ML-coneisolating stimuli varying in spatial frequency is bandpass, with peak activation near the $S$-cone high-frequency cutoff $(0.4 \mathrm{cpd}$ peak, with a response range of $0.025-1.6 \mathrm{cpd}$ ) (Fig. $3 B$ ). These spatial frequency tuning curves also emphasize the large difference in the magnitude of intrinsic signals derived from ML- and $\mathrm{S}$-cone stimulation. At their optimal spatial frequencies, the average strength of ML-cone responses was approximately three times that of S-cone responses.

The population responses to S- and ML-cone-isolating stimuli also exhibited clear differences in temporal properties (Fig. $3 C, D)$. Responsiveness to $\mathrm{S}$-cone stimulation was relatively constant at low temporal frequencies, decreased significantly at drift rates greater than $\sim 5 \mathrm{~Hz}$, and was undetectable at $10 \mathrm{~Hz}$ and higher. Conversely, ML-cone-isolating stimuli were much more effective at eliciting responses at high temporal modulations. At low temporal frequencies, the relative S/ML intrinsic signal modulation magnitude varied across different individuals $(n=3)$, but the high-frequency S-cone falloff is consistent across individual animals. Tuning curve shapes for the S- and ML-isolating stimuli were significantly different (two-factor ANOVA interaction, $p<$ 0.05). These data indicate that, at high temporal frequencies, $\mathrm{S}$-cone stimuli are poorly represented in the visual cortex. The difference between S- and ML-cone activation at high temporal frequencies could be attributable to differences in the temporal properties of the S- and ML- pathways that supply cortex or because the overall level of activity in the S-cone pathway is insufficient to drive cortical responses at high temporal frequencies.

\section{In vivo two-photon imaging of cone-isolating responses}

Although intrinsic imaging is a powerful tool for providing a clear picture of the average responses of neurons, it is unable to reveal responses of the individual neurons that contribute to this aver- age. For example, the correspondence in the orientation maps driven by $\mathrm{S}$ - and ML-cones might arise if all neurons in layer $2 / 3$ received input from S- and ML-cones; alternatively, this correspondence could result from a mixture of neurons, only some of which respond to $\mathrm{S}$-cone stimulation.

To address the distribution of S-cone responses at single-cell resolution, we used two-photon imaging of calcium signals (Fig. $4 A$ ). This technique offers several advantages for the characterization of S-cone inputs. First, previous studies suggest that S-cone inputs to V1 cells might be weak or sparse (Lennie et al., 1990; Johnson et al., 2004; Solomon and Lennie, 2005; HashemiNezhad et al., 2008), and single-cell imaging allows one to characterize responses of dozens of neighboring cells to reveal both abundant and sparse response types. Second, two-photon imaging allows one to record cells located within $300 \mu \mathrm{m}$ of the cortical surface. These superficial cells are difficult to record with electrodes because of dimpling and other factors but are likely to be important for $\mathrm{S}$-cone processing because the K inputs from the LGN specifically target layer 2/3 (Fitzpatrick et al., 1983; Hendry and Carder, 1993; Martin et al., 1997; Chatterjee and Callaway, 2002).

Only a subset of visually responsive layer $2 / 3$ neurons, $\sim 43 \%$ (164 of $383, n=15$ tree shrews), was found to give significant responses to $\mathrm{S}$-cone-isolating gratings $(0.2-0.4 \mathrm{cpd}$, drifting at $2-4 \mathrm{~Hz}$ ). We were unable to discern any spatial pattern to the distribution of S-cone-responsive neurons; they appeared to be intermingled with neurons that were not responsive to $\mathrm{S}$-cone stimulation. Consistent with results from intrinsic imaging, the vast majority of S-cone-responsive neurons were orientation tuned, whether measured with S-cone-isolating or achromatic stimuli. The orientation preference of S-cone-responsive neurons was similar to that of neighboring neurons that were unresponsive to S-cone stimulation (Fig. 4A), and orientation preference values for cells that responded to both achromatic and S-cone-isolating stimulation were not statistically different $(t$ test, $p=0.1$ ). 

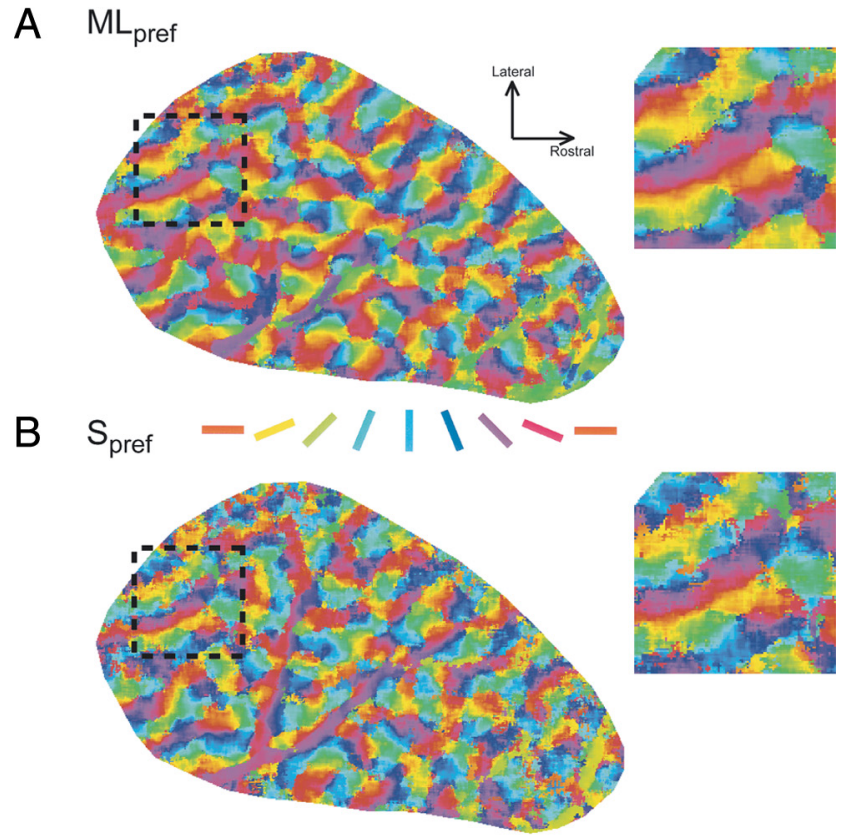

C $\left|M L_{\text {pref }}-S_{\text {pref }}\right|$
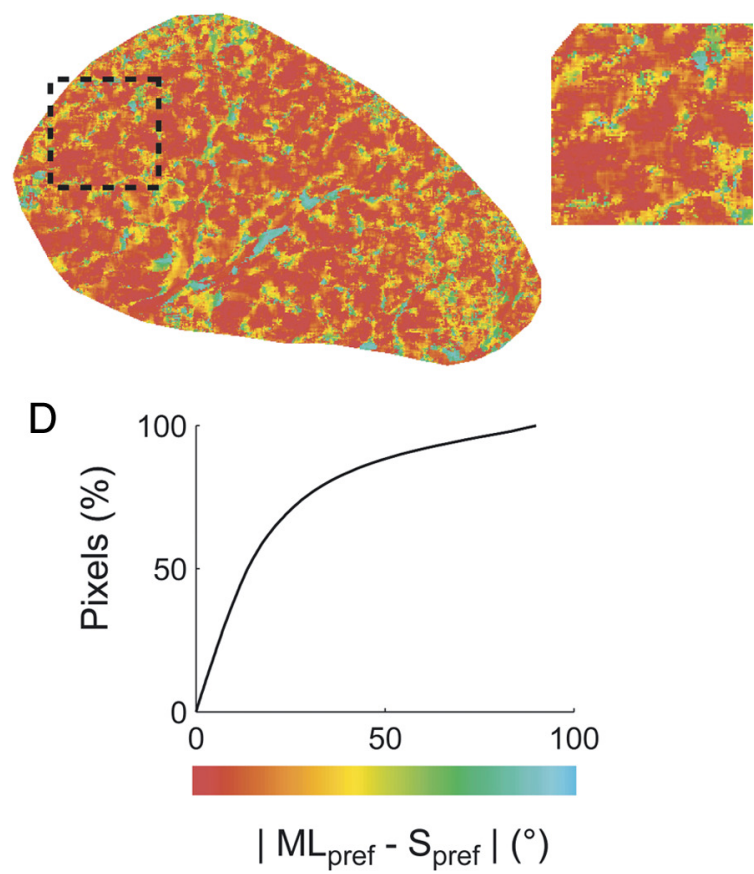

Figure 2. The functional mapping of orientation preference is similar for ML- and S-cone signals. $A, B$, False color orientation maps for one animal constructed from pixel-by-pixel Gaussian fits to intrinsic signal responses. Color indicates orientation preference. ML-cone-isolating gratings were used in $\boldsymbol{A}$ and $\mathrm{S}$-cone-isolating gratings in $\boldsymbol{B}$. $\boldsymbol{C}$, False color map of absolute value of preference differences across the two maps (color scale in $\boldsymbol{D}$ ). $\boldsymbol{D}$, Cumulative histogram of preference differences for one animal. The median pixel exhibits less than a $20^{\circ}$ difference in preference.

Quantitative features of orientation tuning curves that were measured in S-cone-responsive and S-cone-nonresponsive cells were only modestly different, and tuning curve shapes for $\mathrm{S}$-cone-responsive cells that were measured using achromatic or S-cone-isolating gratings were very similar (Fig. 4B). We examined three indices of orientation selectivity: circular variance (the fraction of the total response that occurs at angles other than the preferred), tuning width (the range of orientations to which the cell responds strongly), and orthogonal to preferred ratio (how the tuning curve flanks compare with the peak response) (Fig. 4C). No differences were found in achromatic tuning width or achromatic orthogonal to preferred ratio between S-cone-responsive cells and S-cone-nonresponsive cells (Mann-Whitney test, $p=0.05$ and 0.9 , respectively), but achromatic circular variance values were slightly higher for S-cone-responsive cells (means, 0.37 vs 0.41 ; Mann-Whitney test, $p<0.004)$. Circular variance values measured in S-cone-responsive cells were also modestly larger when measurements were conducted with $\mathrm{S}$-cone-isolating gratings rather than achromatic gratings (means, 0.43 vs 0.37 ; Wilcoxon's signed-rank test, $p<0.001$ ), as were orthogonal to preferred ratios (means, 0.04 vs $0.06 ; p<0.02$ ), but differences in tuning width were not significant $(p=0.9)$.

\section{The diverse chromatic response properties of layer 2/3 neurons}

The results presented so far indicate that many neurons in $\mathrm{V} 1$ are driven by S-cone signals, but they do not reveal the chromatic response properties of $\mathrm{V} 1$ neurons or the nature of interactions between S- and ML-cone signals. Given the color vision capabilities of this species, one would expect that at least some of these S-cone-responsive neurons would exhibit cone-opponent responses, but, in principle, cone-opponent, cone-summing, or single-cone configurations could underlie the responses observed with S-cone-isolating stimulation. To establish the chromatic properties of individual layer $2 / 3$ neurons, two-photon calcium imaging was used to determine the responses of V1 neurons to a family of 12 sinusoidal gratings in which S- and MLcone contrasts and their relative chromatic phases were systematically varied (Fig. 5A) (Diller et al., 2004). S- and MLcone contrasts were presented in-phase at different relative contrasts for stimuli 1-3 and 11-12, whereas S- and ML-cone contrasts were presented out-of-phase for stimuli 5-9. Stimulus 4 provided drive only to S-cones, that is, it was an S-cone-isolating stimulus, whereas stimulus 10 provided drive only to the MLcones (ML-cone-isolating stimulus). This stimulus suite allowed us to explore a wide extent of possible cone interaction space, albeit at a single orientation, spatial and temporal frequency, and stimulus size (the full screen).

Responses from four model neurons are illustrated in Figure $5 B$. A neuron that receives equal drive from $S$ - and ML-cones in an opponent configuration would be expected to exhibit a response peak near stimulus 7 (top left), whereas a neuron that receives similar cone drive in a summing configuration should exhibit peaks at the edges (near stimuli 1 and 11). A neuron that receives excitatory input from S-cones and no input from MLcones should exhibit a peak at stimulus 4 and no response at stimulus 10, and, conversely, a neuron that receives excitatory input from ML-cones but no input from S-cones should exhibit a peak at stimulus 10 and no response to stimulus 4 .

We observed a wide range of responses to this family of gratings. In the imaging field in Figure 5C, neuron $a$ responded strongly to stimuli 7 and 10, whereas neuron $c$ was maximally responsive to stimuli 2 and 12 . Other cells, such as $i-l$, were active for all of these stimuli.

Tuning curves for several cells are shown in Figure 5D. Some neurons $(a, b)$ exhibited peak responses for stimuli 5-9, consistent with opponent interactions, and would be most strongly driven by chromatic boundaries. Others $(c, d)$ exhibited peak responses for stimuli 1-3 or 1-12, consistent with summation of $\mathrm{S}$ - and ML-cones, and would be selective for achromatic boundaries. A few neurons, such as $e$ and $f$, responded to the S-cone- 
A
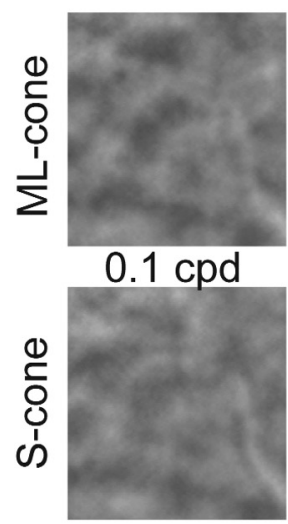

C

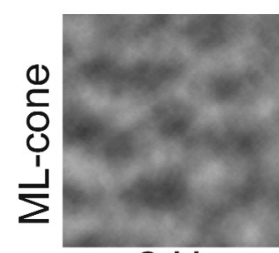

$2 \mathrm{~Hz}$

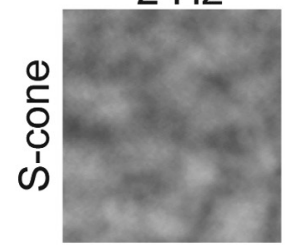

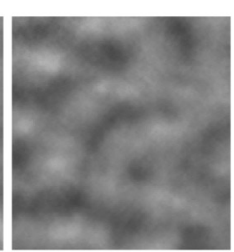
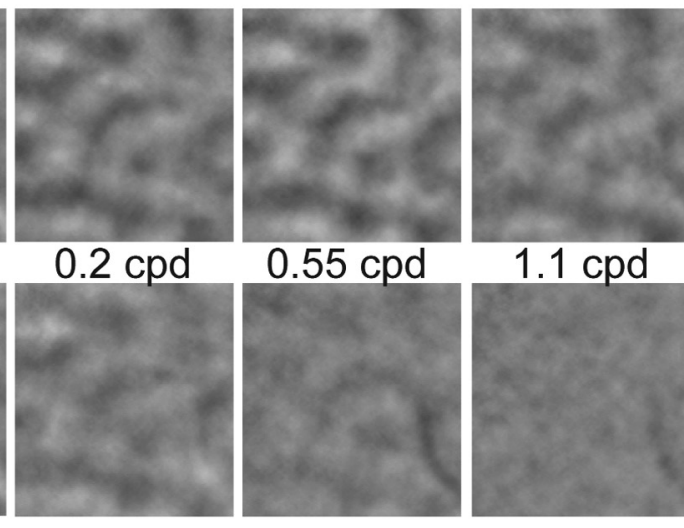

$1.1 \mathrm{cpd}$
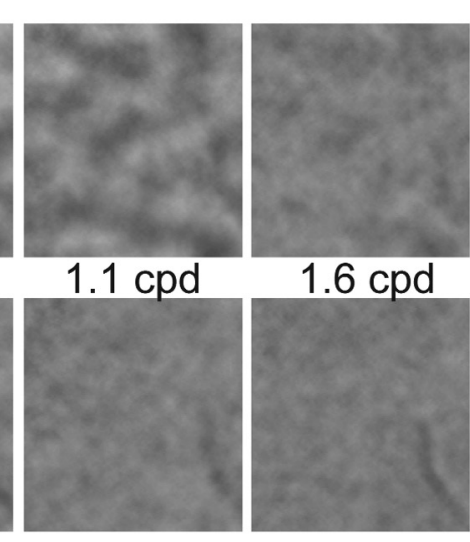

B

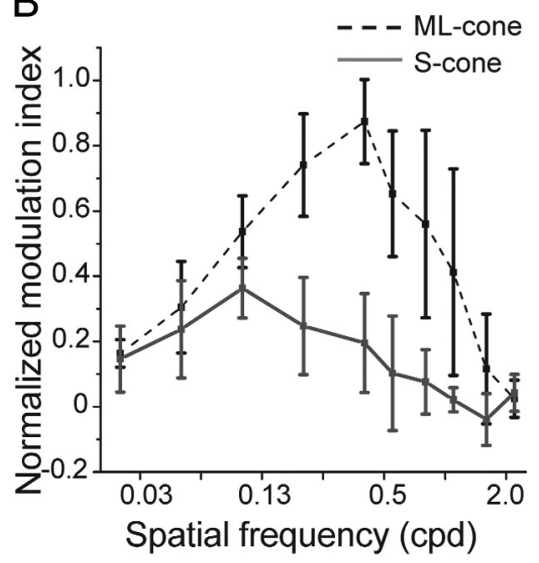

D

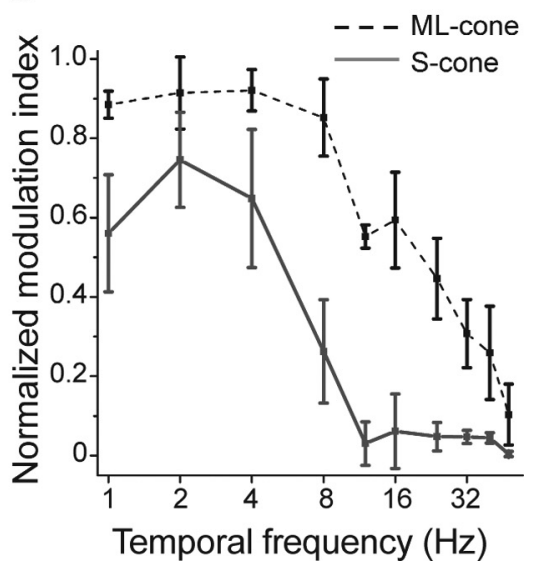

Figure 3. Spatial and temporal frequency population responses are different for $\mathrm{ML}$ - and $\mathrm{S}$-cone signals. $A$, Orientation difference images from the same tree shrew to $\mathrm{S}$ - and $\mathrm{ML}$-cone sinusoidal grating stimuli of varying spatial frequency $(0.1-1.6 \mathrm{cpd})$ and fixed temporal frequency $(2 \mathrm{~Hz})$. S-cone activation is more robust at lower spatial frequencies. $\boldsymbol{B}$, Average normalized activation from $S$ - and ML-cone stimuli of varying spatial frequency ( $n=4$ animals). Note the difference in magnitude of responses to ML-and S-cone stimulation. Error bars indicate SEM. $C$, Orientation difference images from same tree shrew to $S$ - and $M L$-cone gratings of varying temporal frequency (2-32 Hz) and fixed spatial frequency $(0.2 \mathrm{cpd})$. Note falloff of $S$-cone signals at higher temporal rates. $D$, Average normalized activation from $S$ - and ML-cone stimuli of varying temporal frequency ( $n=3$ animals). Relative $S / M L$ response modulation varied across individuals, but high-frequency $S$-cone falloff is consistent. Error bars indicate SEM.

isolating stimulus but exhibited weaker responses when ML-cone signals were included and were particularly suppressed when ML-cone signals were presented out-of-phase from S-cone signals. Several neurons $(g, h)$ responded to stimuli with ML-cone drive but did not respond to the S-cone-isolating stimulus, suggesting that these cells receive input exclusively from ML-cones. Finally, many neurons exhibited broad tuning and responded strongly to all stimuli $(i-l)$. Neurons with these broad tuning curves would be expected to respond to both color and achromatic boundaries.

We next determined whether these response profiles could be divided neatly into discrete classes or spanned a continuum. We developed a cone-summation index that describes how similar the tuning curve of a cell is to the model neuron that has equal cone weights that sum (value 1 ) or has equal cone weights that are opponent (value -1) (see Materials and Methods) (Fig. 5B). We created a similar S/ML response index that describes the similarity of the tuning curve of a cell to the model neuron that has only $\mathrm{S}$-cone drive (1) or only ML-cone drive $(-1)$, as in Figure $5 B$. A scatter plot (Fig. $5 E$ ) indicates a continuum of response profiles.

The scatter plot in Figure $5 E$ also indicates the large variety of these different tuning curve shapes. Cells along the bottom of the graph exhibited strongly opponent responses, whereas cells at the top exhibit summing responses; however, these "purely" opponent or purely summing cells comprise a relatively small percentage of the total population. Cells in the middle of the cone-summation axis are neither purely opponent nor purely summing. Cells on the left of this group exhibit strong responses when presented with strong MLcone drive, whereas cells on the right exhibit strong responses when presented with strong S-cone drive. Cells with broad tuning, located near the center, were most common and make up the densest portion of the plot. There is a continuous distribution of index values, and the median cell (50\%) exhibits some opponency (Fig. 5F).

\section{Modeling the interactions between S- and ML-cone inputs} responsible for chromatic properties of layer $2 / 3$ neurons Whereas the tuning curves emphasize the diverse chromatic response properties of V1 neurons, they do not directly address the interactions between S- and ML-cone inputs that are responsible for a given chromatic response. For example, if a cell receives suppressive input from one cone class, the cell would not respond to the isolating stimulus of that cone, yet the influence of the cone might be clear if its impact were considered across all stimuli. To probe possible underlying cone interactions, we created three simple models of cone inputs (Fig. 6A,B). For all models, we supposed that each cell received linear input from the two cone types. Although responses from our grating stimuli do not allow us to infer the exact spatial configuration of cone inputs in the 


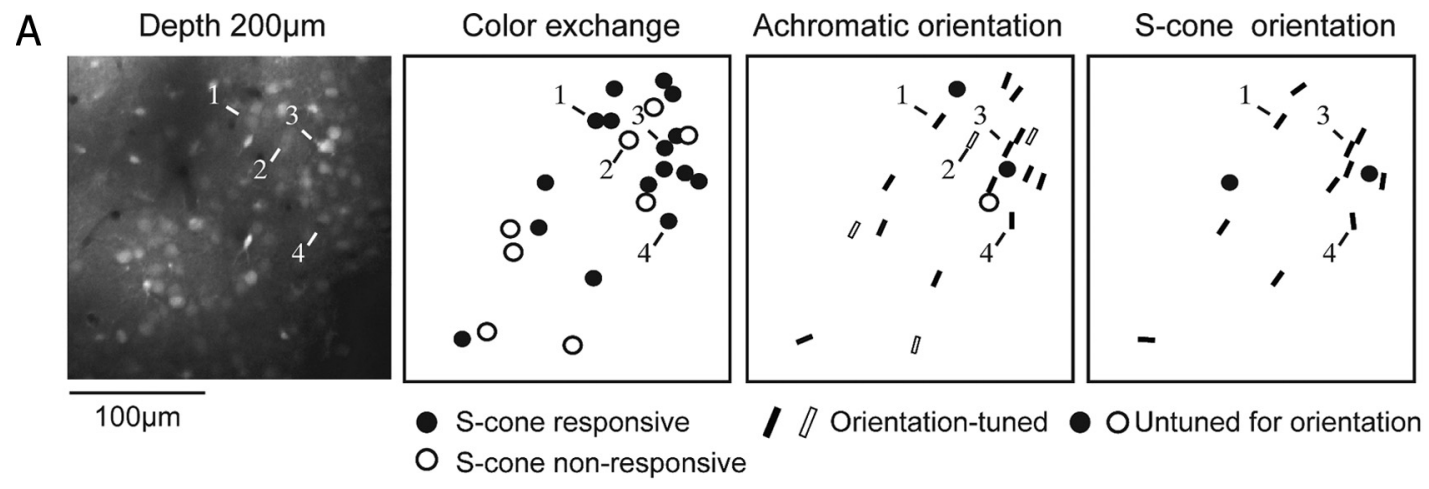

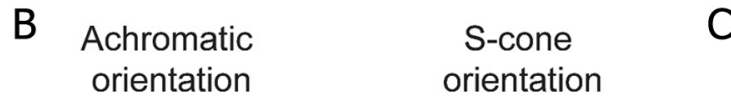
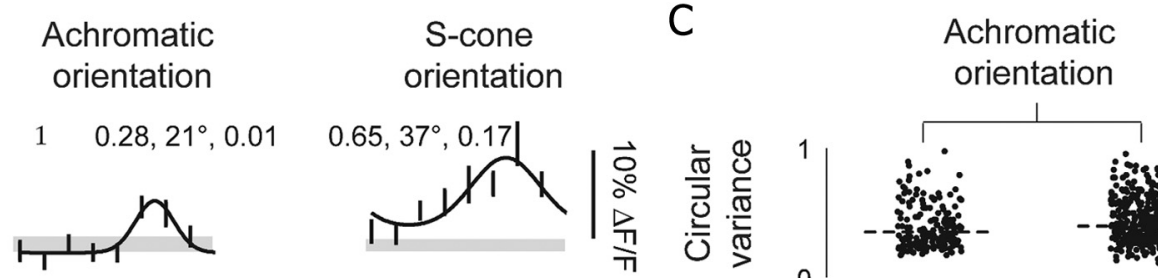

$20.38,17^{\circ}, 0.01$

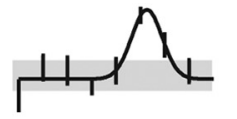

$30.23,41^{\circ},-0.2$

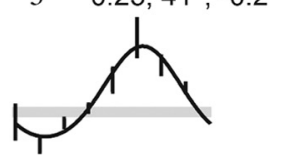

$4 \quad 0.35,33^{\circ},-0.07$

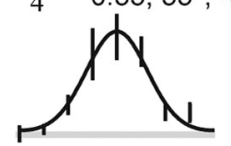

$-\backslash 1 /$
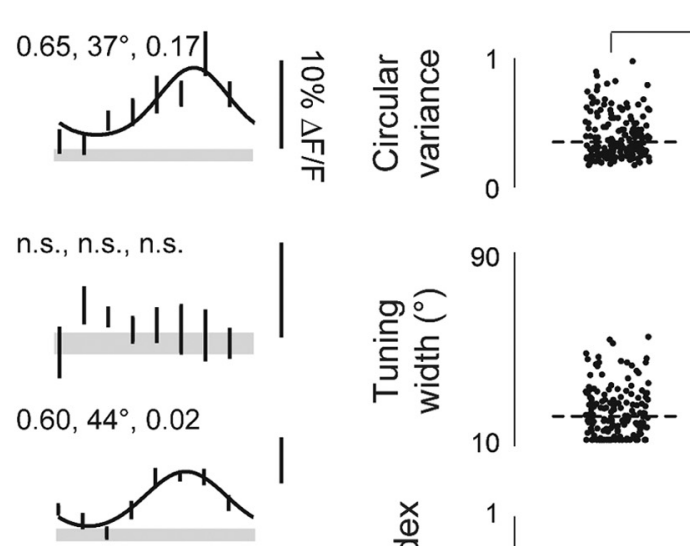

$\frac{x}{0}$
$\frac{0}{5}$
$\frac{0}{0}$

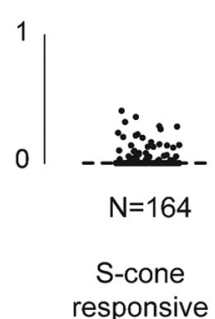

$\cdot$

$0.45,32^{\circ}, 0.04$

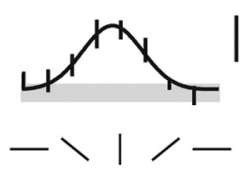

responsive

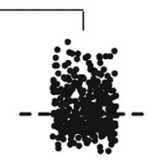

\section{S-cone \\ orientation}
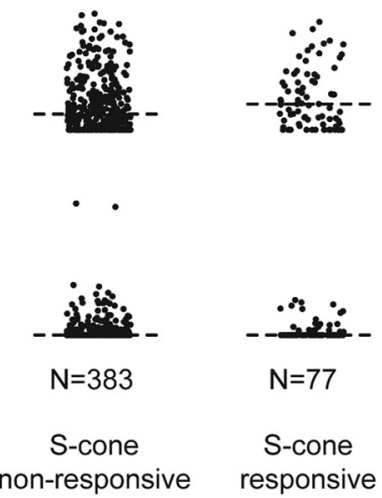

Figure 4. A subset of V1 neurons exhibit S-cone responses. A, Left, two-photon image of cells labeled with calcium dye Oregon green BAPTA-1. Middle left, Schematic of responses to an S-cone-isolating stimulus. Filled circles, Neurons that exhibited significant responses to color-exchange stimulus (see Materials and Methods) and also exhibited significant responses to properly oriented S-cone-isolating grating. Open circles, Neurons that exhibited significant responses to the color-exchange stimulus but did not exhibit significant responses to $\mathrm{S}$-cone-isolating gratings. Middle right, Achromatic orientation responses. Cells were included if they gave significant visual responses to both color-exchange and oriented gratings compared with the blank stimulus (ANOVA, $p<0.05$ ). Bars indicate cells that exhibited significant variation across the oriented gratings (ANOVA, $p<0.05$ ), and the orientation of the bar matches the orientation preference of each cell. Right, S-cone-isolating orientation responses. B, Achromatic and S-cone-isolating orientation tuning curves for four cells indicated in $\boldsymbol{A}$. Circular variance, tuning width (half-width at half-height), and orthogonal-to-preferred (0/P) ratio are shown for each curve. Cell 2 did not exhibit significant variation across the S-cone-isolating gratings so no fitting was performed. $C$, Scatter plots of circular variance, tuning width, and orthogonal-to-preferred ratio for all cells. Dashed lines indicate median values. Parameters were relatively similar for all conditions, although circular variance was slightly higher for S-cone-responsive cells (see Results).

cells, for ease of presentation, we assumed that the spatial extent of the receptive field matched the spatial period of our gratings and then divided the receptive field profile for each cone type into two halves; at any particular time, one-half of the receptive field was stimulated by one-half phase of the sinusoidal grating, and the other half of the receptive field was stimulated by the opposite phase. To estimate the response to the drifting gratings by a cell we used in our experiments, we added the responses of the simulated cell to two temporal phases of the grating stimulus, $0^{\circ}$ and $180^{\circ}$, corresponding to the times when the grating was aligned with the receptive field profile. To compute the response of the cell to a grating at each of these temporal phases, we multiplied the signed grating cone contrast for each cone type by its cone weight, added these values, and rectified above 0 to account for the spike threshold.
In the simplest model, the CC model, responses depended only on the relative phase and contrasts of S- and ML-cone input, which could have different weights. In equation form, $\mathrm{R}_{\mathrm{cc}}\left(\mathrm{S}_{\mathrm{c}}\right.$, $\left.M L_{c}\right)=M L_{w} M_{c}+S_{w} S_{c}$, where $S_{c}$ and $M_{c}$ are the $S$ - and ML-cone contrasts of the stimulus, and $S_{w}$ and $M_{\mathrm{w}}$ are the free cone weights (two free parameters total). In the spatial configuration presented in Figure $6 \mathrm{~A}$, this meant the two halves of the receptive field for each cone were required to be equal and opposite, but one could also imagine other configurations, such as cone projections to a single linear subunit. If the S- and ML-cone inputs summed, then the weights $\mathrm{S}_{\mathrm{w}}$ and $\mathrm{ML}_{\mathrm{w}}$ shared the same sign; if the cones were opponent, then $S_{w}$ and $\mathrm{ML}_{\mathrm{w}}$ had opposite signs.

The CC model could describe the tuning curves of many cells that might have been expected from previous studies, such as single-opponent (opponency in cone type or space but not both), 
A
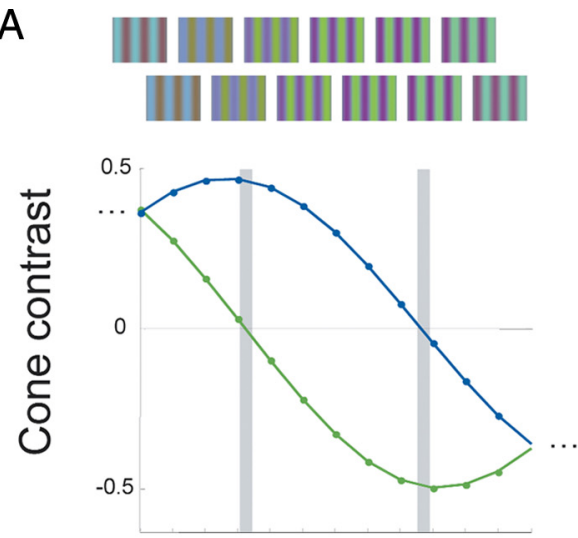

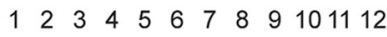

Stimulus number
B
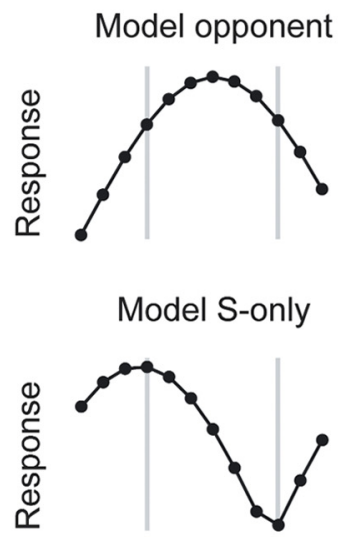

Stimulus number
Model summing

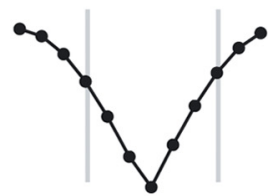

Model ML-only

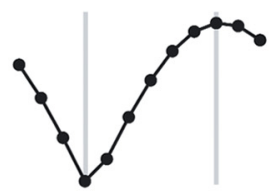

$\begin{array}{llllll}1 & 3 & 5 & 7 & 9 & 11\end{array}$

Stimulus number

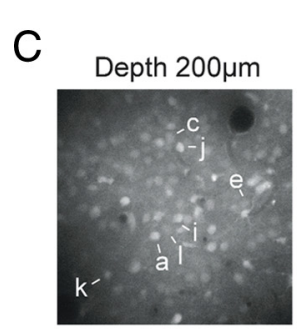

Stimulus 2
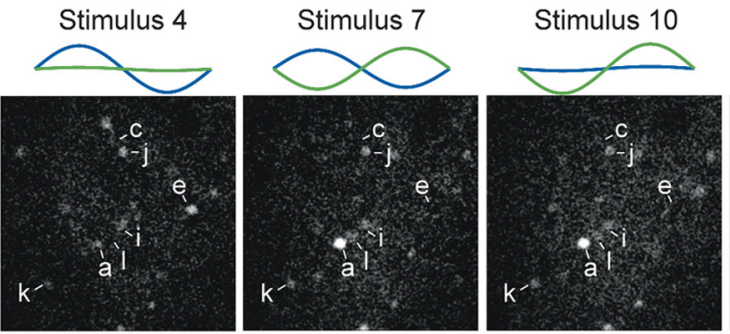

Stimulus 12
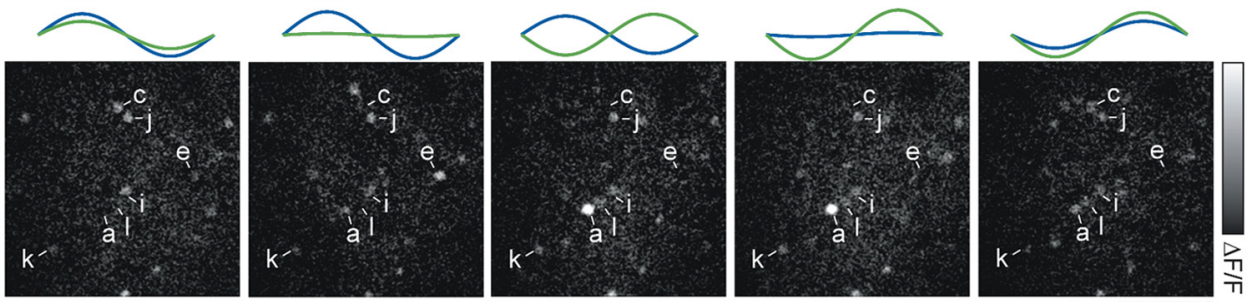

D

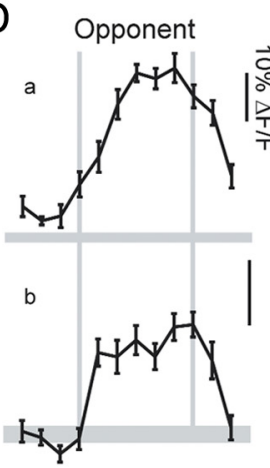

S-cone selective

ML-cone dominated

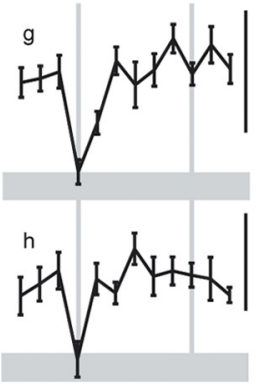

$\begin{array}{llllll}1 & 3 & 5 & 7 & 9 & 11\end{array}$

Stimulus number
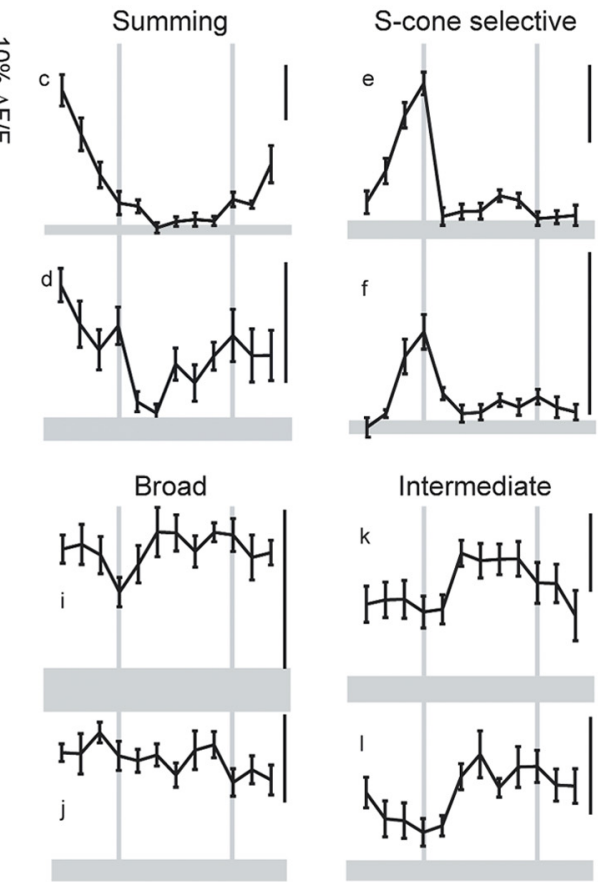

$\begin{array}{llllll}1 & 3 & 5 & 7 & 9 & 11\end{array}$

Stimulus number
E

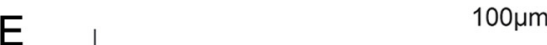<smiles>CNN</smiles>

F

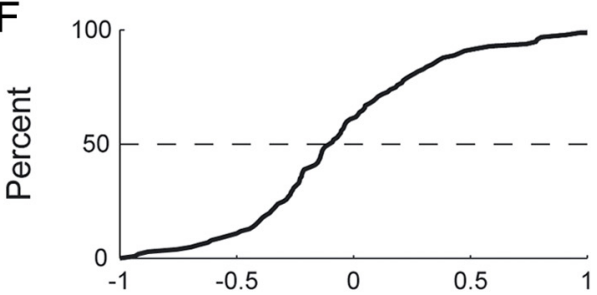

Cone summation index

Figure 5. Visual cortical cells exhibit a diversity of $S / M L$ chromatic tuning responses. $A$, Stimulation consisted of combinations of S-cone and ML-cone contrasts presented in-phase and out-of-phase. $\boldsymbol{B}$, Predicted responses of model neurons to the stimulus suite in $\boldsymbol{A}$. $\boldsymbol{C}$, Responses to several stimuli in one animal. Left, Raw baseline image of cells; other images show change in fluorescence relative to baseline image. Note that different cells in field respond to different combinations of stimuli. $\boldsymbol{D}$, Tuning curves from 12 representative neurons. Chromatic tuning ranges from opponent, summing, or ML-only to broadly tuned or S-cone selective. E, Plot of index values derived directly from stimulus responses (cone-summing index and $S / M L$ response index) indicates a continuous distribution of chromatic tuning. $\boldsymbol{F}$, Broad distribution of cone-summing index; few cells exhibited purely summing or purely opponent chromatic tuning. 
A

Cone contrast model

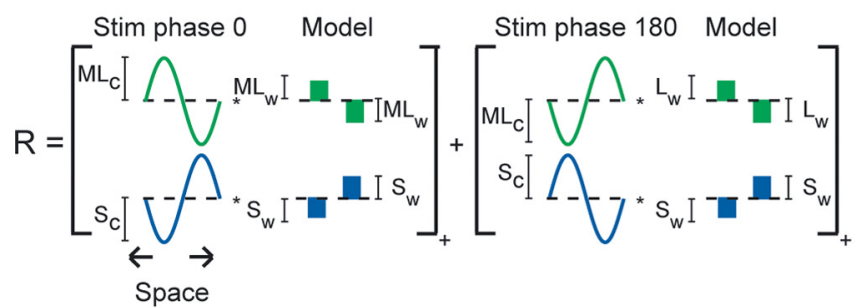

C

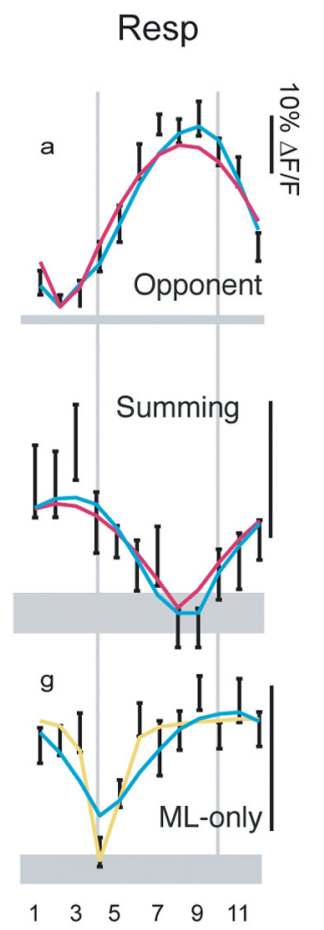

Stimulus number

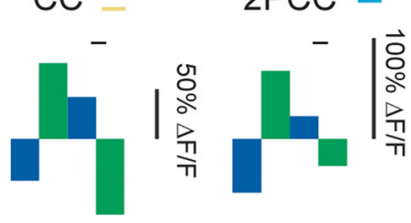

GOF $=96 \%{ }^{*} \quad$ GOF $=98 \%$
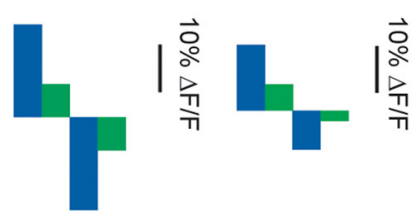

GOF $=88 \%$ *

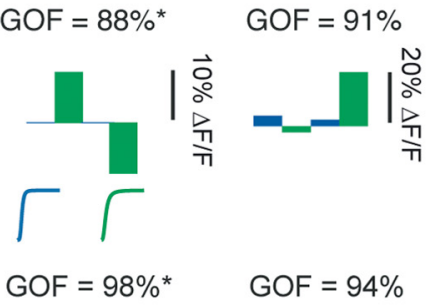

GOF $=98 \%$ *

GOF $=94 \%$
B

2-phase cone contrast model

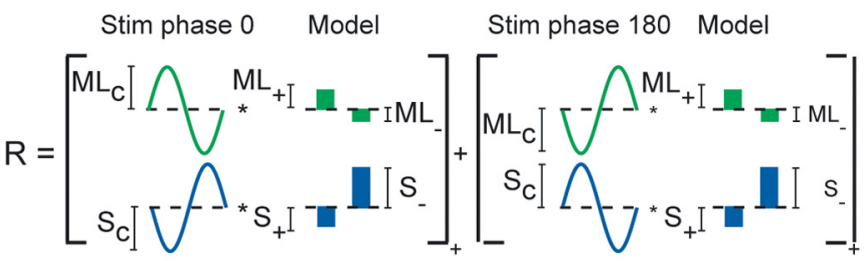

D

Resp

$\mathrm{CC}=2 \mathrm{PCC}-$
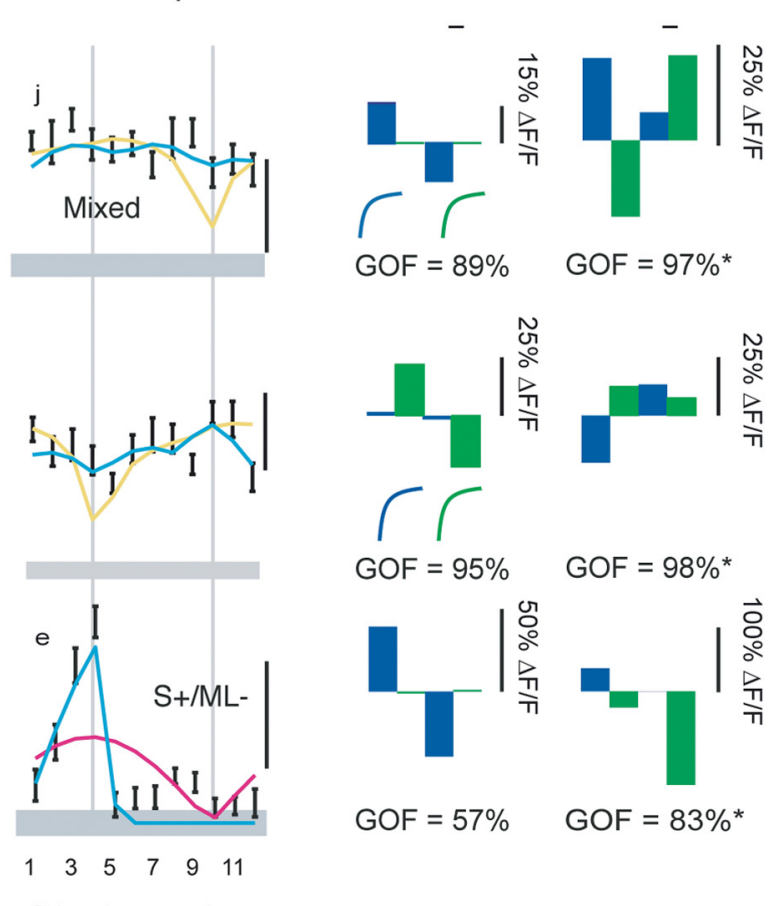

GOF $=57 \% \quad$ GOF $=83 \%$ *

\footnotetext{
-
}

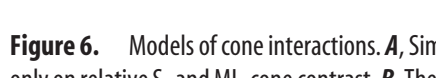
inly on relative $S$ - and $M L$-cone the $C($ model. Tuning curve along are well fit by mixed summing/opponent configurations,

double-opponent (opponency in cone opponent (summing) cells (Fig. 6C) number of cells were not described adeq model. Some cells, such as the cell in could be well fit by the CC model only ift to include nonlinear cone contrast gain $H\left(c, n, c_{50}\right)=c^{n} /\left(c^{n}+c_{50}{ }^{n}\right)$. The modif had six free parameters: two cone weight S-cone contrast, and $n$ and $c_{50}$ for the

Although the response profiles of neurons $(51.4 \%)$ were best described by model, the responses of many neuro compatible with these models. To fit cells, we created an extended model, contrast model (2PCC), which posited th subunits that are not equal and model, $R_{2 p}\left(\mathrm{~S}_{\mathrm{c}}, \mathrm{ML}_{\mathrm{c}}\right)=\left[\mathrm{S}_{+}\left[\mathrm{S}_{\mathrm{c}}\right]_{+}+\mathrm{S}_{-}\right.$ $\left.\mathrm{ML}_{-}\left[-\mathrm{ML}_{\mathrm{c}}\right]_{+}\right]_{+}+\left[\mathrm{S}_{+}\left[-\mathrm{S}_{\mathrm{c}}\right]_{+}+\mathrm{S}_{-}\right.$ $\left.\mathrm{ML}_{-}\left[\mathrm{ML}_{\mathrm{c}}\right]_{+}\right]_{+}$, where $\mathrm{S}_{+}, \mathrm{S}_{-}, \mathrm{ML}_{+}$, weights and $[x]_{+}$denotes rectification above
Stimulus number

\title{
Stimulus number
}

\author{
(2)
}

(1)

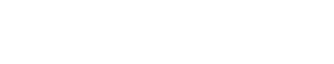



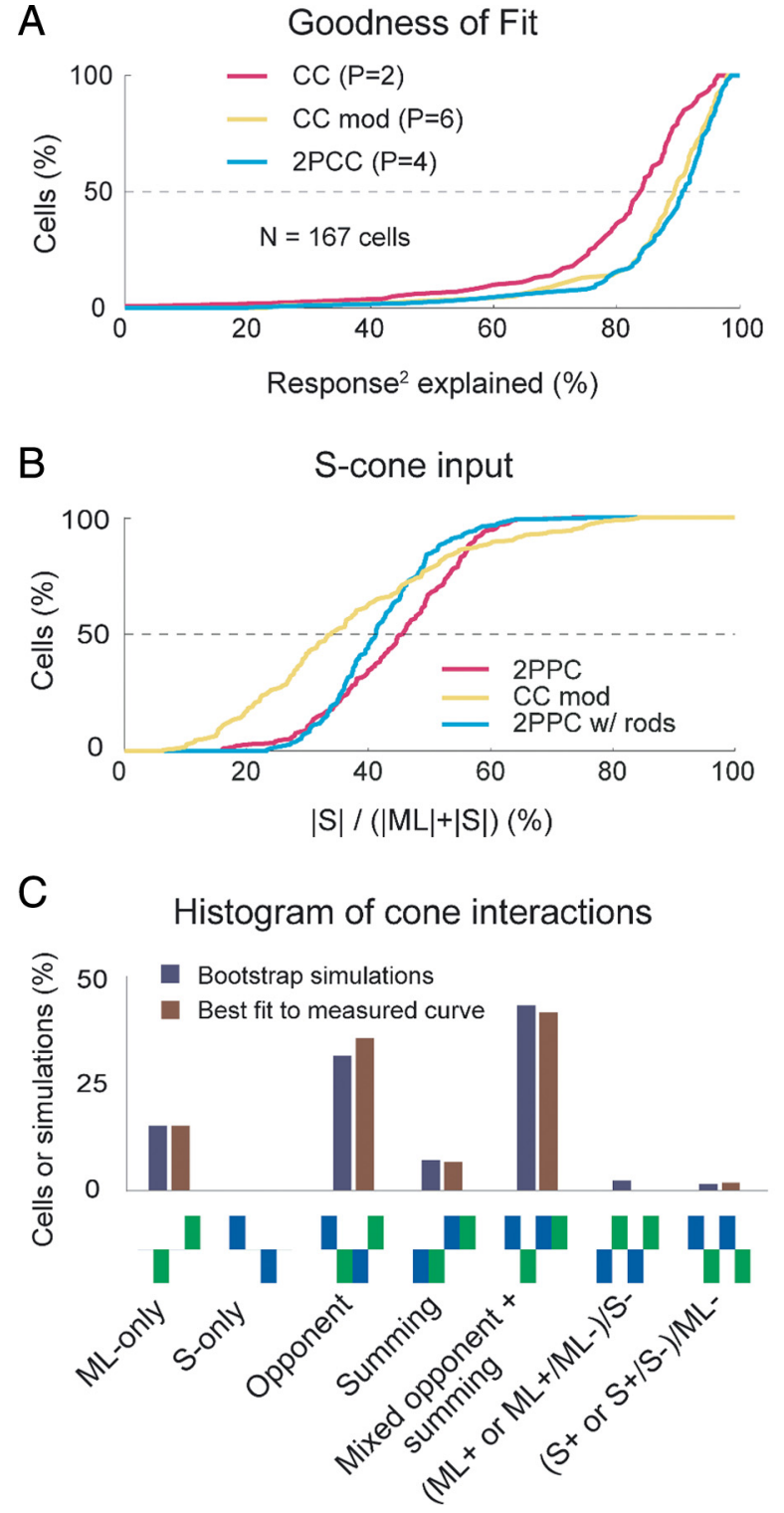

D Orientation selectivity and cone interactions

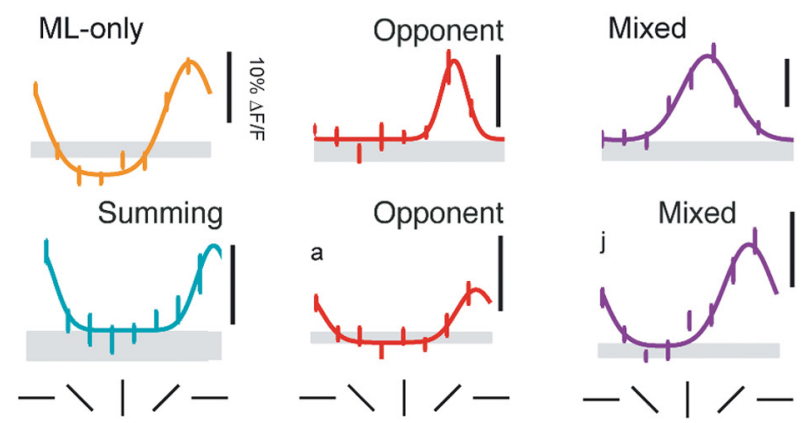

E Orientation selectivity and cone interactions
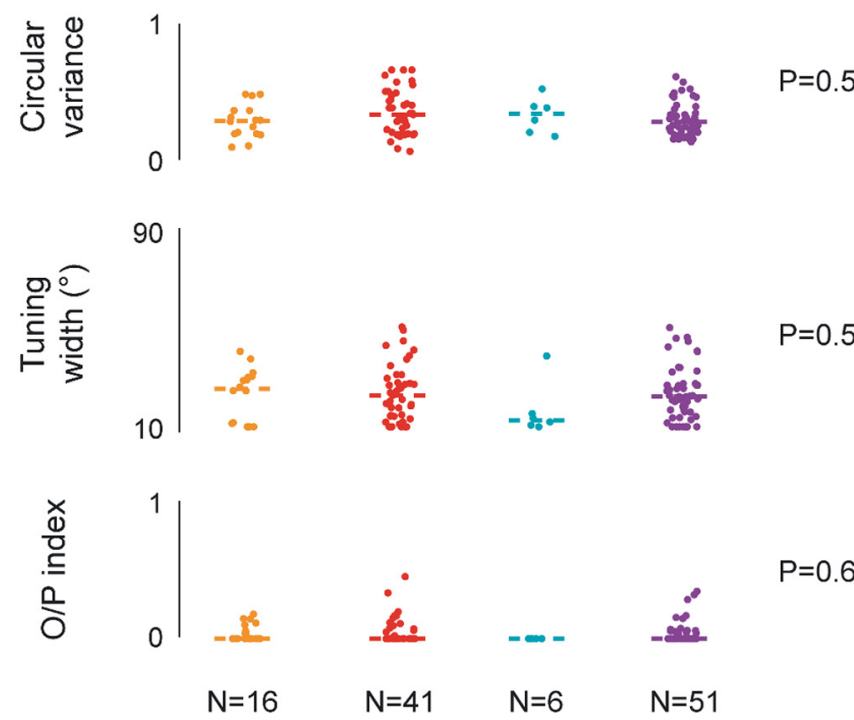

ML-only Opponent Summing Mixed

Figure 7. V1 cells exhibit a variety of S/ML-cone configurations. $A$, Cumulative histogram of goodness of fit for models. All models do well, but $2 \mathrm{PCC}$ model explains $>90 \%$ of responses for median cell. $\boldsymbol{B}$, Cumulative histogram of fraction of total cone input attributable to $S$-cones for the modified CC model, 2 PCC model, and 2PCC model extended to include rods. Some $34-46 \%$ of cone input to median cell is derived from S-cones. C, Histogram of cone interactions in best model for mean fits and bootstrap simulations (see Results). Most common configuration is mixed summing/opponent, followed by opponent configuration, ML-only, and summing. $\boldsymbol{D}$, Orientation tuning curves from cells with different cone input configurations. $\boldsymbol{E}$, Orientation tuning curve parameters for the four most common configurations; no significant differences among these groups were observed (Kruskal-Wallis test $p$ values shown). 0/P, Orthogonal-to-preferred ratio.

models accounted for a considerable portion of observed responses; the median goodness of fit ranged from $84 \%$ for the CC model to $91 \%$ for the 2 PCC model (Fig. $7 A$ ). We estimate that the median cell received somewhere between 34 and $46 \%$ of its total cone input from S-cones (Fig. $7 B$ ). This estimate did not change substantially if we expanded the 2 PPC model to include contributions from the rods, suggesting that our decision to ignore rod contributions in the stimulus design was reasonable.

We next determined the best model description for each cell using a modified nested $F$ test (Fig. $7 C$ ). The most common fit type was the "mixed-opponent/summing" configuration that described the broad tuning curves, followed by "opponent" and "ML only." To ensure that the best model description for the measured responses of a cell was not influenced unduly by trialto-trial variation, we also computed the best model for 100 bootstrap simulations for all cells (Press et al., 1992) and observed a similar distribution of best model fits. These results indicate that the most common cell type observed in our study is not a member of the "traditional" classes of purely color-selective or achromatic-selective neurons.

Finally, we examined whether there was a relationship between cone interaction type and orientation selectivity. All of the cone interaction types exhibited orientation selectivity (Fig. $7 D, E)$, and the distribution of observed tuning parameters, such as circular variance, tuning width, and orthogonal/preferred index, did not vary significantly across the cone interaction types (Fig. 7E). This result suggests that one would expect all of these cell types to exhibit elongated receptive fields.

\section{Discussion}

These results indicate that large numbers of layer $2 / 3$ neurons respond to $\mathrm{S}$-cone-isolating stimuli and that these responses are 
well tuned for orientation and exhibit spatiotemporal tuning properties distinct from ML-cone responses. Our analysis also suggests that neurons combine $\mathrm{S}$ - and $\mathrm{ML}$-cone inputs in a range of configurations, including summation, opponency, and other configurations that do not fit this dichotomy. These observations are difficult to reconcile with the view that S-cones contribute exclusively to a color channel and that color and form information are processed separately within V1 circuits.

\section{$\mathrm{S}$-cones provide a substantial input to layer $2 / 3 \mathrm{~V} 1$ neurons} One unexpected result that emerged was how effectively S-cone stimulation modulated responses in V1. S-cones comprise $<10 \%$ of cones (McCrane et al., 1983; Curcio et al., 1991; Petry et al., 1993), and a small number of LGN neurons appear to be S-cone responsive (De Valois et al., 2000a; Hendry and Reid, 2000; Calkins, 2001; Hashemi-Nezhad et al., 2008; Szmajda et al., 2008; Tailby et al., 2008c), leading one to predict a weak cortical representation. The fraction of V1 neurons reported to exhibit S-cone responses in primates varies, but there is general agreement that, for those cells, S-cone inputs account for $<10 \%$ of the total cone input (Lennie et al., 1990; Johnson et al., 2004; Solomon and Lennie, 2005; Hashemi-Nezhad et al., 2008). Our intrinsic imaging results indicate that population activity driven by S-coneisolating stimuli can be $30 \%$ as strong as that from cone-contrastmatched ML-cone-selective stimuli, and our two-photon results indicate that $\sim 40 \%$ of layer $2 / 3$ neurons respond effectively to $\mathrm{S}$-cone-isolating stimuli. Moreover, responses to the systematic variation of S- and ML-cone contrasts indicates that the fraction of cells whose responses are modulated by S-cone activity could be as high as $85 \%$, with the median cell receiving as much as $34-46 \%$ of its total cone input from S-cones. The higher percentage of S-cone drive observed here compared with previous studies in primates may reflect species differences, the superficial population of neurons we sampled, or nonlinearities in calcium dynamics, but we feel that it is most likely a result of the fact that we used stimuli that combine many cone contrasts and phases. The idea that S-cone signals might be amplified by cortical circuits has been raised in fMRI studies (Kleinschmidt et al., 1996; Engel et al., 1997; Wandell, 1999; Liu and Wandell, 2005; Mullen et al., 2007, 2008; Sumner et al., 2008) and is also consistent with some single-unit studies in macaque (Cottaris and De Valois, 1998; De Valois et al., 2000b) and squirrel (Heimel et al., 2005) and with observations from a recent intrinsic signal imaging study in dichromatic marmosets (Buzas et al., 2008).

\section{S-cone cortical responses exhibit distinct spatiotemporal tuning properties}

Human psychophysical studies have shown that vision mediated by $\mathrm{S}$-cones has lower spatial resolution than vision mediated by longer wavelength cones, consistent with the coarse retinal S-cone sampling (Williams and Collier, 1983; Hess et al., 1989; Curcio et al., 1991). The tree shrew visual system exhibits lower spatial resolution than most primates, but the percentage of $\mathrm{S}$-cones is comparable, and the coarse retinal sampling is reflected in lower spatial frequency preferences in the S-cone population response compared with the ML-cone response.

Temporal frequency responses to S-cone stimulation also differ from those of ML-cone stimulation: $\mathrm{S}$-cone responses exhibit a steep falloff for frequencies $>8 \mathrm{~Hz}$, whereas ML-cone responses persist for the highest frequencies tested $(40-48 \mathrm{~Hz})$. The falloff for S-cone responses is consistent with psychophysical and fMRI studies that extrapolated this value for the human S-cone system (Brindley et al., 1966; Wisowaty and Boynton, 1980; Engel et al.,
1997; Liu and Wandell, 2005). The basis for the difference in temporal tuning remains unclear. S-cone photoreceptors do not appear to differ from ML-cones in their temporal tuning (Schnapf et al., 1990), nor do ganglion cells that are activated by S-cone inputs (Yeh et al., 1995). However, a recent study of macaque LGN neurons that were activated by S-cone and achromatic modulation noted a lower peak sensitivity for S-cone inputs, suggesting that the poor temporal resolution of the S-cone pathway might arise in the retina (Tailby et al., 2008b).

\section{Layer 2/3 neurons display a diverse array of cone interactions}

Because of these limitations in spatiotemporal properties, it is often assumed that the principal contribution of the S-cone system is to color vision. Indeed, we find that many layer $2 / 3$ neurons exhibit cone-opponent tuning properties that are ideally suited for extracting chromatic information. However, we also find cells that sum the two cone types, suggesting that S-cone inputs also contribute to achromatic signals. Electrophysiological evidence for a contribution of S-cones to the luminance channel in primates remains controversial, with some studies providing evidence that neurons in magnocellular LGN layers sum inputs from S-, M-, and L-cones (Chatterjee and Callaway, 2002), whereas other studies find no S-cone input to these neurons (Chatterjee and Callaway, 2003; Reid and Shapley, 2002; Hashemi-Nezhad et al., 2008; Tailby et al., 2008a,c). The contribution of S-cones to luminance perception has also been contentious (Eisner and MacLeod, 1980; Verdon and Adams, 1987; Lee and Stromeyer, 1989; Stockman et al., 1991), but it now seems clear that S-cones do make contributions under certain conditions.

Although cone-opponent and cone-summing configurations have dominated descriptions of cone interactions, our results emphasize that the majority of layer $2 / 3$ neurons exhibit $S$ - and ML-cone responses that are neither purely color opponent nor purely summing. These properties resemble cells in primate V1 that respond to modulation of both luminance and color (Thorell et al., 1984; Johnson et al., 2001, 2004, 2008; Horwitz et al., 2005, 2007). We have shown that the mixed tuning curves we encountered could be well described by a two-phase linear receptive field model that combines cone-opponent and -summing inputs, followed by rectification. Similar models were suggested by others (Shapley and Hawken, 2002; Horwitz et al., 2007) to explain the color-luminance properties of the red/green-sensitive V1 neurons they encountered, and this model might explain alterations in chromatic tuning after chromatic habituation (Tailby et al., 2008a).

These receptive field configurations could, in principle, arise from linear LGN-type inputs that converge in the configurations posited in the model or could be built up in stages within the cortex through convergence of opponent and summing channels. Whatever mechanisms are responsible, our results emphasize that S-cone responses are not limited to a cone-opponent pathway but contribute to $\mathrm{V} 1$ responses that are likely relevant to perception of both chromatic and achromatic signals, a feature that is shared with the ML-opponent system in primates despite differences in the routes by which these cone signals gain access to cortical circuits.

\section{S-cone inputs drive orientation-selective responses in V1}

The relation between orientation selectivity and color selectivity of V1 neurons remains a matter of debate. Historically, form vision was viewed as depending primarily on achromatic information supplied by neurons that are sensitive to edges defined by 
luminance (Livingstone and Hubel, 1984; Ts'o and Gilbert, 1988; Lennie et al., 1990), but some recent studies report that cells can exhibit orientation selectivity regardless of whether or not they exhibit color selectivity (Thorell et al., 1984; Leventhal et al., 1995; Johnson et al., 2001, 2008; Friedman et al., 2003; Heimel et al., 2005; Conway and Livingstone, 2006). Much of this work has focused on the ML system in primates, and it could be argued that the orientation tuning that is present in the ML-cone-opponent system is an epiphenomenon of evolution, reflecting the relatively recent incorporation of color opponency into a parvocellular pathway that was specialized for high acuity form vision. The present results demonstrate that orientation tuning is not unique to the ML-opponent pathway and are consistent with a study in V1 of another dichromat - the gray squirrel-that reported identical orientation selectivity in cone-opponent and non-opponent neurons (Heimel et al., 2005). Our results are also consistent with recent $\mathrm{fMRI}$ and psychophysical studies in humans that provide evidence for orientation-selective responses to S-cone-isolating stimuli in V1 (Beaudot and Mullen, 2005; Huang et al., 2007; Sumner et al., 2008; Wade, 2009).

The fact that both the ML- and S-opponent systems exhibit joint selectivity for orientation and color implies that extraction of borders defined only by chromatic differences affords significant advantages for visually guided behaviors. Although it has been argued that equiluminant edges are rare in nature, a recent analysis of natural scenes indicates that equiluminant edges are no more rare than pure luminance edges (Hansen and Gegenfurtner, 2009). Indeed, most edges are defined by both luminance and chromatic information but to varying degrees, such that luminance and chromatic edges are statistically independent of each other. Perhaps the combination of orientation tuning with a broad distribution of achromatic and chromatic sensitivities that includes pure opponent, pure summing, and various mixtures provides an optimal match for the chromatic and luminance edge statistics of natural scenes.

\section{Lack of modular specialization for S-cone inputs in tree shrew visual cortex}

In primates, information derived from S-cone-opponent retinal ganglion cells is relayed to cortical circuits by neurons in the K-cell layers of the LGN (Martin et al., 1997), which project to the CO-rich patches, or "blobs," in cortical layer $2 / 3$ and to layer $4 \mathrm{~A}$ of V1 (Fitzpatrick et al., 1983). Electrophysiological results indicate that both areas receive inputs from S-cone-responsive LGN afferents (Chatterjee and Callaway, 2003). Several studies suggested that $\mathrm{CO}$ blobs are rich in color-selective neurons that are poorly tuned for orientation (Livingstone and Hubel, 1984; Ts'o and Gilbert, 1988), but most of this work has focused on stimuli that are effective at driving ML-opponent responses; other studies fail to find a difference in the coloropponent properties of blob versus interblob regions (Lennie et al., 1990; Leventhal et al., 1995).

To our knowledge, only one study (in marmoset) has used S-cone-isolating stimuli to probe modular organization in V1, and this study did not find evidence of modular segregation of S-cone responses (Buzas et al., 2008). It is worth noting that the geniculo-cortical pathway in tree shrews resembles the K-cell pathway in primates, including the presence of LGN neurons that respond to S-cone-isolating stimuli (our unpublished data) and projections that terminate in the superficial layers of V1 (Usrey et al., 1992). However, these inputs are not arranged in a modular manner, and there is no evidence for CO blobs in layer $2 / 3$ of tree shrew V1 (Wong-Riley and Norton, 1988). Thus, a uniform pattern of population responses to $S$-cone-isolating stimuli would be expected in tree shrew V1. We were not able to discern a spatial organization of S-cone-opponent and -summing neurons in our two-photon imaging experiments; rather, we found that neighboring neurons frequently exhibited different S-cone configurations. With the caveat that we sampled only from the superficial parts of layer $2 / 3$, the evolution of S-cone chromatic responses per se does not appear to have been linked with the emergence of CO blobs, a point that receives support from the fact that the blob system is robust in layer $2 / 3$ of primates that lack a functional S-cone pathway (Tootell et al., 1985). With color, as for other properties such as orientation and direction, species differences illustrate the independence of columnar architecture and the synaptic mechanisms that are responsible for selective cortical response properties (Horton and Adams, 2005).

\section{References}

Beaudot WH, Mullen KT (2005) Orientation selectivity in luminance and color vision assessed using 2-d band-pass filtered spatial noise. Vision Res 45:687-696.

Bosking WH, Zhang Y, Schofield B, Fitzpatrick D (1997) Orientation selectivity and the arrangement of horizontal connections in tree shrew striate cortex. J Neurosci 17:2112-2127.

Bosking WH, Crowley JC, Fitzpatrick D (2002) Spatial coding of position and orientation in primary visual cortex. Nat Neurosci 5:874-882.

Brainard DH (1997) The psychophysics toolbox. Spat Vis 10:433-436.

Brindley GS, Du Croz JJ, Rushton WA (1966) The flicker fusion frequency of the blue-sensitive mechanism of colour vision. J Physiol 183:497-500.

Buzas P, Szmajda BA, Hashemi-Nezhad M, Dreher B, Martin PR (2008) Color signals in the primary visual cortex of marmosets. J Vis 8:7.1-7.16.

Calkins DJ (2001) Seeing with S cones. Prog Retin Eye Res 20:255-287.

Carandini M, Ferster D (2000) Membrane potential and firing rate in cat primary visual cortex. J Neurosci 20:470-484.

Chatterjee S, Callaway EM (2002) S cone contributions to the magnocellular visual pathway in macaque monkey. Neuron 35:1135-1146.

Chatterjee S, Callaway EM (2003) Parallel colour-opponent pathways to primary visual cortex. Nature 426:668-671.

Conway BR, Livingstone MS (2006) Spatial and temporal properties of cone signals in alert macaque primary visual cortex. J Neurosci 26:10826-10846.

Cottaris NP, De Valois RL (1998) Temporal dynamics of chromatic tuning in macaque primary visual cortex. Nature 395:896-900.

Curcio CA, Allen KA, Sloan KR, Lerea CL, Hurley JB, Klock IB, Milam AH (1991) Distribution and morphology of human cone photoreceptors stained with anti-blue opsin. J Comp Neurol 312:610-624.

Dacey DM, Packer OS (2003) Colour coding in the primate retina: diverse cell types and cone-specific circuitry. Curr Opin Neurobiol 13:421-427.

de Monasterio FM (1979) Asymmetry of on-pathway and off-pathway of blue-sensitive cones of the retina of macaques. Brain Res 166:39-48.

Derrington AM, Krauskopf J, Lennie P (1984) Chromatic mechanisms in lateral geniculate nucleus of macaque. J Physiol 357:241-265.

De Valois RL, Cottaris NP, Elfar SD, Mahon LE, Wilson JA (2000a) Some transformations of color information from lateral geniculate nucleus to striate cortex. Proc Natl Acad Sci U S A 97:4997-5002.

De Valois RL, Cottaris NP, Mahon LE, Elfar SD, Wilson JA (2000b) Spatial and temporal receptive fields of geniculate and cortical cells and directional selectivity. Vision Res 40:3685-3702.

Diller L, Packer OS, Verweij J, McMahon MJ, Williams DR, Dacey DM (2004) L and M cone contributions to the midget and parasol ganglion cell receptive fields of macaque monkey retina. J Neurosci 24:1079-1088.

Eisner A, MacLeod DI (1980) Blue-sensitive cones do not contribute to luminance. J Opt Soc Am 70:121-123. 
Engel S, Zhang X, Wandell B (1997) Colour tuning in human visual cortex measured with functional magnetic resonance imaging. Nature 388:68-71.

Estévez O, Spekreijse H (1982) The "silent substitution" method in visual research. Vision Res 22:681-691.

Field GD, Sher A, Gauthier JL, Greschner M, Shlens J, Litke AM, Chichilnisky EJ (2007) Spatial properties and functional organization of small bistratified ganglion cells in primate retina. J Neurosci 27:13261-13272.

Fitzpatrick D (1996) The functional organization of local circuits in visual cortex: insights from the study of tree shrew striate cortex. Cereb Cortex 6:329-341.

Fitzpatrick D, Itoh K, Diamond IT (1983) The laminar organization of the lateral geniculate body and the striate cortex in the squirrel monkey (Saimiri sciureus). J Neurosci 3:673-702.

Friedman HS, Zhou H, von der Heydt R (2003) The coding of uniform colour figures in monkey visual cortex. J Physiol 548:593-613.

Green DG, Powers MK, Banks MS (1980) Depth of focus, eye size and visual acuity. Vision Res 20:827-835.

Hansen T, Gegenfurtner KR (2009) Independence of color and luminance edges in natural scenes. Vis Neurosci 26:35-49.

Hashemi-Nezhad M, Blessing EM, Dreher B, Martin PR (2008) Segregation of short-wavelength sensitive ("blue") cone signals among neurons in the lateral geniculate nucleus and striate cortex of marmosets. Vision Res 48:2604-2614.

Heimel JA, Van Hooser SD, Nelson SB (2005) Laminar organization of response properties in primary visual cortex of the gray squirrel (Sciurus carolinensis). J Neurophysiol 94:3538-3554.

Hendry SH, Carder RK (1993) Neurochemical compartmentation of monkey and human visual cortex: similarities and variations in calbindin immunoreactivity across species. Vis Neurosci 10:1109-1120.

Hendry SH, Reid RC (2000) The koniocellular pathway in primate vision. Annu Rev Neurosci 23:127-153.

Hess RF, Mullen KT, Zrenner E (1989) Human photopic vision with only short wavelength cones: post-receptoral properties. J Physiol 417:151-172.

Horton JC, Adams DL (2005) The cortical column: a structure without a function. Philos Trans R Soc Lond B Biol Sci 360:837-862.

Horwitz GD, Chichilnisky EJ, Albright TD (2005) Blue-yellow signals are enhanced by spatiotemporal luminance contrast in macaque V1. J Neurophysiol 93:2263-2278.

Horwitz GD, Chichilnisky EJ, Albright TD (2007) Cone inputs to simple and complex cells in V1 of awake macaque. J Neurophysiol 97:3070-3081.

Huang PC, Mullen KT, Hess RF (2007) Collinear facilitation in color vision. J Vis 7:6.1-6.14.

Humphrey AL, Skeen LC, Norton TT (1980) Topographic organization of the orientation column system in the striate cortex of the tree shrew (Tupaia glis). II. Deoxyglucose mapping. J Comp Neurol 192:549-566.

Jacobs GH, Neitz J (1986) Spectral mechanisms and color vision in the tree shrew (Tupaia belangeri). Vision Res 26:291-298.

Johnson EN, Hawken MJ, Shapley R (2001) The spatial transformation of color in the primary visual cortex of the macaque monkey. Nat Neurosci 4:409-416.

Johnson EN, Hawken MJ, Shapley R (2004) Cone inputs in macaque primary visual cortex. J Neurophysiol 91:2501-2514.

Johnson EN, Hawken MJ, Shapley R (2008) The orientation selectivity of color-responsive neurons in macaque V1. J Neurosci 28:8096-8106.

Kleinschmidt A, Lee BB, Requardt M, Frahm J (1996) Functional mapping of color processing by magnetic resonance imaging of responses to selective P- and M-pathway stimulation. Exp Brain Res 110:279-288.

Lee J, Stromeyer CF 3rd (1989) Contribution of human short-wave cones to luminance and motion detection. J Physiol 413:563-593.

Lennie P, Krauskopf J, Sclar G (1990) Chromatic mechanisms in striate cortex of macaque. J Neurosci 10:649-669.

Leventhal AG, Thompson KG, Liu D, Zhou Y, Ault SJ (1995) Concomitant sensitivity to orientation, direction, and color of cells in layers 2, 3, and 4 of monkey striate cortex. J Neurosci 15:1808-1818.

Li Y, Van Hooser SD, Mazurek M, White LE, Fitzpatrick D (2008) Experience with moving visual stimuli drives the early development of cortical direction selectivity. Nature 456:952-956.

Liu J, Wandell BA (2005) Specializations for chromatic and temporal signals in human visual cortex. J Neurosci 25:3459-3468.

Livingstone MS, Hubel DH (1984) Anatomy and physiology of a color system in the primate visual cortex. J Neurosci 4:309-356.
Malpeli JG, Schiller PH (1978) Lack of blue OFF-center cells in the visual system of the monkey. Brain Res 141:385-389.

Martin PR, White AJ, Goodchild AK, Wilder HD, Sefton AE (1997) Evidence that blue-on cells are part of the third geniculocortical pathway in primates. Eur J Neurosci 9:1536-1541.

McCrane EP, de Monasterio FM, Schein SJ, Caruso RC (1983) Nonfluorescent dye staining of primate blue cones. Invest Ophthalmol Vis Sci 24:1449-1455.

Mullen KT, Dumoulin SO, McMahon KL, de Zubicaray GI, Hess RF (2007) Selectivity of human retinotopic visual cortex to S-coneopponent, L/M-cone-opponent and achromatic stimulation. Eur J Neurosci 25:491-502.

Mullen KT, Dumoulin SO, Hess RF (2008) Color responses of the human lateral geniculate nucleus: [corrected] selective amplification of S-cone signals between the lateral geniculate nucleno and primary visual cortex measured with high-field fMRI. Eur J Neurosci 28:1911-1923.

Müller B, Peichl L (1989) Topography of cones and rods in the tree shrew retina. J Comp Neurol 282:581-594.

Muly EC, Fitzpatrick D (1992) The morphological basis for binocular and ON/OFF convergence in tree shrew striate cortex. J Neurosci 12:1319-1334.

Peichl L (2005) Diversity of mammalian photoreceptor properties: adaptations to habitat and lifestyle? Anat Rec A Discov Mol Cell Evol Biol 287:1001-1012.

Pelli DG (1997) The VideoToolbox software for visual psychophysics: transforming numbers into movies. Spat Vis 10:437-442.

Petry HM, Hárosi FI (1990) Visual pigments of the tree shrew (Tupaia belangeri) and greater galago (Galago crassicaudatus): a microspectrophotometric investigation. Vision Res 30:839-851.

Petry HM, Kelly JP (1991) Psychophysical measurement of spectral sensitivity and color vision in red-light-reared tree shrews (Tupaia belangeri). Vision Res 31:1749-1757.

Petry HM, Erichsen JT, Szél A (1993) Immunocytochemical identification of photoreceptor populations in the tree shrew retina. Brain Res 616:344-350.

Press WH, Flannery BP, Teukolsky SA, Vetterling WT (1992) Numerical recipes in C. Cambridge, UK: Cambridge UP.

Reid RC, Shapley RM (2002) Space and time maps of cone photoreceptor signals in macaque lateral geniculate nucleus. J Neurosci 22:6158-6175.

Schnapf JL, Nunn BJ, Meister M, Baylor DA (1990) Visual transduction in cones of the monkey Macaca fascicularis. J Physiol 427:681-713.

Shapley R, Hawken M (2002) Neural mechanisms for color perception in the primary visual cortex. Curr Opin Neurobiol 12:426-432.

Solomon SG, Lennie P (2005) Chromatic gain controls in visual cortical neurons. J Neurosci 25:4779-4792.

Stockman A, MacLeod DI, DePriest DD (1991) The temporal properties of the human short-wave photoreceptors and their associated pathways. Vision Res 31:189-208.

Sumner P, Anderson EJ, Sylvester R, Haynes JD, Rees G (2008) Combined orientation and colour information in human V1 for both L-M and S-cone chromatic axes. Neuroimage 39:814-824.

Szmajda BA, Buzás P, Fitzgibbon T, Martin PR (2006) Geniculocortical relay of blue-off signals in the primate visual system. Proc Natl Acad Sci U S A 103:19512-19517.

Szmajda BA, Grünert U, Martin PR (2008) Retinal ganglion cell inputs to the koniocellular pathway. J Comp Neurol 510:251-268.

Tailby C, Solomon SG, Dhruv NT, Lennie P (2008a) Habituation reveals fundamental chromatic mechanisms in striate cortex of macaque. J Neurosci 28:1131-1139.

Tailby C, Solomon SG, Lennie P (2008b) Functional asymmetries in visual pathways carrying S-cone signals in macaque. J Neurosci 28:4078-4087.

Tailby C, Szmajda BA, Buzás P, Lee BB, Martin PR (2008c) Transmission of blue $(S)$ cone signals through the primate lateral geniculate nucleus. J Physiol 586:5947-5967.

Thorell LG, De Valois RL, Albrecht DG (1984) Spatial mapping of monkey V1 cells with pure color and luminance stimuli. Vision Res 24:751-769.

Tootell RB, Hamilton SL, Silverman MS (1985) Topography of cytochrome oxidase activity in owl monkey cortex. J Neurosci 5:2786-2800.

Ts'o DY, Gilbert CD (1988) The organization of chromatic and spatial interactions in the primate striate cortex. J Neurosci 8:1712-1727. 
Usrey WM, Muly EC, Fitzpatrick D (1992) Lateral geniculate projections to the superficial layers of visual cortex in the tree shrew. J Comp Neurol 319:159-171.

Valberg A, Lee BB, Tigwell DA (1986) Neurones with strong inhibitory S-cone inputs in the macaque lateral geniculate nucleus. Vision Res 26:1061-1064.

van Arsdel RE, Loop MS (2004) Color vision sensitivity in normally dichromatic species and humans. Vis Neurosci 21:685-692.

Verdon W, Adams AJ (1987) Short-wavelength-sensitive cones do not contribute to mesopic luminosity. J Opt Soc Am A 4:91-95.

Wade AR (2009) Long-range suppressive interactions between S-cone and luminance channels. Vision Res 49:1554-1562.

Wandell BA (1999) Computational neuroimaging of human visual cortex. Annu Rev Neurosci 22:145-173.
Williams DR, Collier R (1983) Consequences of spatial sampling by a human photoreceptor mosaic. Science 221:385-387.

Wisowaty JJ, Boynton RM (1980) Temporal modulation sensitivity of the blue mechanism: measurements made without chromatic adaptation. Vision Res 20:895-909.

Wong-Riley MT, Norton TT (1988) Histochemical localization of cytochrome oxidase activity in the visual system of the tree shrew: normal patterns and the effect of retinal impulse blockage. J Comp Neurol 272:562-578.

Yeh T, Lee BB, Kremers J (1995) Temporal response of ganglion cells of the macaque retina to cone-specific modulation. J Opt Soc Am A Opt Image Sci Vis 12:456-464.

Zrenner E, Gouras P (1981) Characteristics of the blue sensitive cone mechanism in primate retinal ganglion cells. Vision Res 21: 1605-1609. 